Article

\title{
Rate Decline Analysis for Limited-Entry Well in Abnormally High-Pressured Composite Naturally Fractured Gas Reservoirs
}

\author{
Mingtao Wu ${ }^{1,2}$, Xiaodong Wang ${ }^{1, *}$, Wenqi Zhao ${ }^{3}$, Lun Zhao ${ }^{3}$, Meng Sun ${ }^{3}$ and Hai Zhou ${ }^{2}$ \\ 1 School of Energy Resources, China University of Geosciences (Beijing), Beijing 100083, China; \\ wumt@cugb.edu.cn \\ 2 Beijing Key Laboratory of Unconventional Natural Gas Geological Evaluation and Development \\ Engineering, China University of Geosciences (Beijing), Beijing 100083, China; zhouhai@cugb.edu.cn \\ 3 Research Institute of Petroleum Exploration and Development, PetroChina, Beijing 100083, China; \\ zhaowenqi@petrochina.com.cn (W.Z.); zhaolun@petrochina.com.cn (L.Z.); mickfoleypia@163.com (M.S.) \\ * Correspondence: wxd_cug@cugb.edu.cn; Tel.: +86-10-8232-2754
}

Received: 31 March 2019; Accepted: 29 April 2019; Published: 1 May 2019

\begin{abstract}
Most naturally fractured gas reservoirs in China exhibit strongly heterogeneous, abnormally high-pressured and, stress-sensitive behaviors. In this work, a semianalytical solution is developed to study the production performance for limited-entry well in composite naturally fractured formations. The pressure-dependent porosity and permeability, anisotropy and limited-entry characteristics are taken into consideration. Furthermore, conventional Warren-Root model is amended to accommodate for permeability anisotropy. Laplace and finite Fourier cosine transforms are used to solve the diffusivity equations. The model is verified on the basis of previous literature's results and data of a field example from Moxi gas field in Southwest China. Through the parameters sensitivity analysis, the effects of prevailing factors on production performance are investigated. Results indicate that a large inner region radius and high mobility ratio can improve gas production rate in the early stage, while they also lead to a drastic decline of production rate in the late stage. Large permeability stress-dependent coefficient and low penetrated interval both have a negative impact on production rate. With its high efficiency and simplicity, this proposed approach can serve as a convenient tool to evaluate the behavior of partially penetrated production well in abnormally high-pressured composite naturally fractured gas reservoirs.
\end{abstract}

Keywords: rate decline analysis; naturally fractured gas reservoir; partially penetrated well; composite reservoirs

\section{Introduction}

Whether $\mathrm{CO}_{2}$ geological sequestration, disposal of high-level radioactive waste, or exploitation of geothermal and hydrocarbon resources, all of them are associated with fractured reservoirs [1-3]. Therefore, it is increasingly significant to understand fluid flow behavior through naturally fractured reservoir in hydrology, environment, and petroleum engineering. Especially, with the development of natural gas exploration and exploitation in the world, the proven reserves and production of naturally fractured gas reservoirs are increasing year by year [4].

The majority of naturally fractured gas reservoirs exhibit abnormally high-pressured as a result of disequilibrium compaction [5]. In China, Kela-2 gas field in Tarim Basin and Moxi gas field in Sichuan Basin which have been developed for several years are both abnormally high-pressured fractured gas reservoirs. Due to the characteristics of abnormal pressure, the rock and fluid properties of naturally fractured gas reservoirs are commonly pressure-dependent. 
With microseismic monitoring and transient pressure analysis, it is demonstrated that some naturally fractured gas reservoirs may exhibit composite properties in the radial direction. That is, a large number of natural fractures exist near the wellbore area while the outer region far away from well has fewer ones [6]. Therefore, a composite model is appropriate to analyze the production performance of the well. Composite reservoir models were originally targeted to model special reservoir configuration consisting of two or more concentric zones with different diffusivities or fluid properties. As early as 1960, Hurst [7] developed the analytical solution for radially composite reservoirs in which the storativity ratio between two regions are identical. Two decades later, Olarewaju and Lee $[8,9]$ proposed an analytical solution to analyze pressure transient behavior for wells in finite composite reservoir system. Besides the composite formation with single porosity media in inner and outer regions, many researchers [10-14] also developed the mathematical model for composite dual-porosity reservoirs. Subsequently, Kuchuk and Habashy [15] solved fluid flow problems in composite reservoirs by reflection and transmission theory of electromagnetics. In recent years, composite model is applied to describe stimulated region volume around well in unconventional reservoirs [16-18].

Unfortunately, most literature aimed at studying fully penetrated wells in composite reservoirs. Nevertheless, some wells in actual fields were partially penetrated especially in thick formations. For the research of partially penetrated wells, extensive works were carried out in hydrology and petroleum engineering. Muskat [19] first investigated steady flow through porous media for partially penetrated vertical well. Nisle [20] and Brons and Marting [21] studied the effect of partial penetration on the pressure drawdown and buildup of oil wells in an isotropic layer with no-flow boundary conditions at the top and bottom of the layer. Odeh [22] established the steady-state flow model of partially penetrated well by Fourier transforms. Kazemi and Seth [23] studied the combined effect of anisotropy and stratification with crossflow on pressure response for partially penetrated well. With Laplace and Hankel transforms, Streltsova [24-26] solved the unsteady-state flow problems for partially penetrated well. The Laplace transform was also used by Dougherty and Babu [27] to analyze hydraulics problem for a partially penetrated well in a dual-porosity reservoir. Bui et al. [28] developed an analytical solution to analyze transient pressure behavior of partially penetrated wells in naturally fractured reservoirs with infinite radial extent. Based on the solution of Bui et al. [28], a set of pressure derivative type curves were generated by Slimani and Tiab [29]. Recently, Mishra et al. [30] studied the radial flow to a partially penetrated well with storage in an anisotropic confined aquifer. Biryukov and Kuchuk [31] presented an analytical pressure transient solution for a limited-thickness open cylindrical interval on a nonpermeable cylindrical wellbore. In their model, the mixed boundary value problems were investigated. Javandel [32] proposed a semianalytical solution for partial penetration in two layer aquifers. Dejam et al. [33] studied the effect of a constant top pressure on the pressure transient analysis of a partially penetrated well in an infinite-acting fractured reservoir with wellbore storage and skin factor effects. However, most of them merely investigated transient pressure behavior for partially penetrated well in oil reservoirs or aquifers. Despite the great efforts presented in the aforementioned literature, the rate decline analysis model for partially penetrated wells in composite gas reservoir is lacking, particularly in stress-sensitive composite naturally fractured gas reservoir.

The objective of this paper is to develop a semianalytical model for rate decline analysis of partially penetrated well in abnormally high-pressured composite naturally fractured gas reservoirs. By the definition of pseudopressure function and pseudotime factor, fluid and rock pressure-dependent properties were taken into consideration. Laplace and finite Fourier cosine transforms were used to solve the 2D diffusivity equation. Based on the proposed model, the effects of prevailing factors on production performance were investigated. Finally, some remarkable conclusions are drawn. 


\section{Mathematical Model}

\subsection{Preliminaries}

Fracture tends to close when pressure drops during the process of fluid extraction. Thus, the permeability of fracture in naturally fractured gas reservoirs may notably decrease [34-37]. The explicit relationship can be determined by a stress-sensitive experiment [35], and the corresponding experimental results are shown in Figure 1. Based on the curve matching of experimental results, a common approach to account for permeability variations can be written as:

$$
k=k_{i} e^{-\gamma_{k}\left(p_{i}-p\right)}
$$

where, $p_{i}$ and $p$ denote initial and current reservoir pressure, respectively; $k_{i}$ and $k$ denote permeability at initial and current reservoir pressure, respectively; $\gamma_{k}$ denotes permeability stress-sensitivity coefficient and is assumed to be constant.

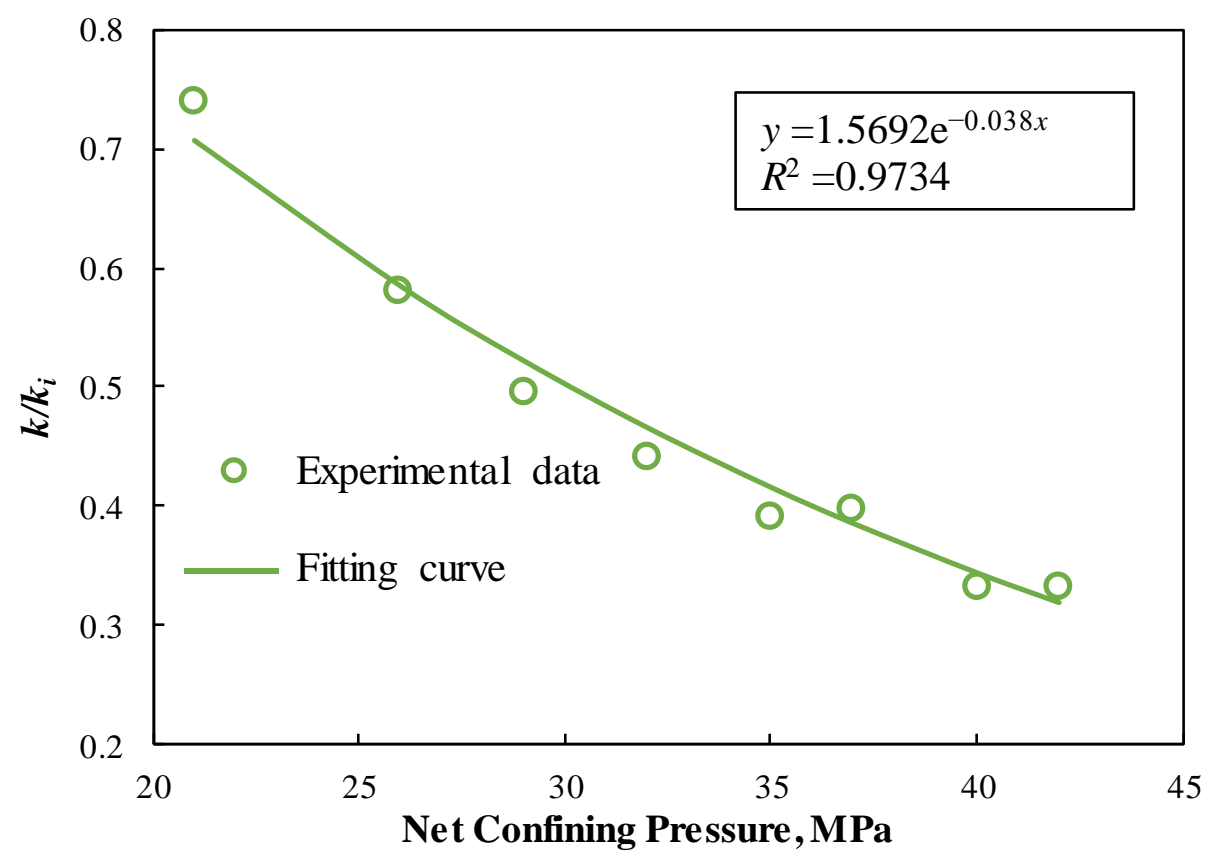

Figure 1. Experimental data [35] matching for permeability of naturally fractured gas reservoir.

Furthermore, gas flow through porous media is essentially nonlinear because the properties of gas are strongly dependent on pressure. Conventionally, pseudopressure and pseudotime methods are used to linearize the diffusivity equation of gas [38-42]. In this paper, novel definitions of pseudopressure function and pseudotime factor are proposed incorporating pressure-dependent porosity and permeability as follows respectively:

$$
\begin{gathered}
p_{p}=\frac{\mu_{g i} Z_{i}}{k_{i} p_{i}} \int_{p_{s c}}^{p} \frac{k p}{\mu_{g} Z} d p \\
\beta=\frac{1}{t} \frac{\varphi_{i} c_{t i} \mu_{g i}}{k_{i}} \int_{0}^{t} \frac{k}{\varphi c_{t} \mu_{g}} d t
\end{gathered}
$$

where, $p_{p}$ denotes gas pseudopressure function; $k_{i}$ and $k$ denote permeability at initial and current reservoir pressure, respectively, following Equation (1); $Z_{i}$ and $Z$ denote gas deviation factor at initial 
and current reservoir pressure, respectively; $\mu_{g i}$ and $\mu_{g}$ denote gas viscosity at initial and current reservoir pressure, respectively; $\beta$ denotes gas pseudotime factor; $\varphi_{i}$ and $\varphi$ denote porosity at initial and current reservoir pressure, respectively; $c_{t i}$ and $c_{t}$ denote total compressibility at initial and current reservoir pressure, respectively.

The calculations of pseudopressure and pseudotime factor need to solve material balance equation for abnormally high-pressured naturally fractured gas reservoir [43]:

$$
\frac{p}{Z}\left\{1-\left[\left(1-\frac{G_{f}}{G_{t}}\right) c_{m}+\frac{G_{f}}{G_{t}} c_{f}\right]\left(p_{i}-p\right)\right\}=\frac{p_{i}}{Z_{i}}\left(1-\frac{G_{p}}{G_{t}}\right)
$$

where, $G_{p}$ denotes cumulative production; $G_{f}$ and $G_{t}$ denote original gas in place that is stored in fracture system and total original gas in place, respectively; $c_{m}$ and $c_{f}$ denote matrix and fracture system compressibility, respectively.

\subsection{Physical Model and Basic Assumptions}

As shown in Figure 2, a partially penetrated vertical well is located in the center of a circular naturally fractured gas reservoir. The reservoir is assumed to have two regions: Inner region and outer region, in which reservoir properties are drastically different. The radius of the inner region is $R_{1}$, and the radius of the whole system is $R_{e}$. The inner region consists of fractures and matrix while the outer region consists of matrix only, provided that the transfer flow between matrix and fractures in inner region is pseudosteady state. Besides, both of the two regions possess permeability anisotropies. Apart from the aforementioned description, some other assumptions are elaborated as:

(1) The reservoir is horizontal with uniform thickness of $h$;

(2) The upper and bottom boundaries of reservoir are impermeable, and outer boundary is also closed;

(3) The water phase is assumed to be immobile, which means the gas production process is single phase flow;

(4) The well is a line source and only part of it produces, and its perforation interval is $h_{\mathrm{w}}$;

(5) The effect of gravity and capillary pressure are ignored.

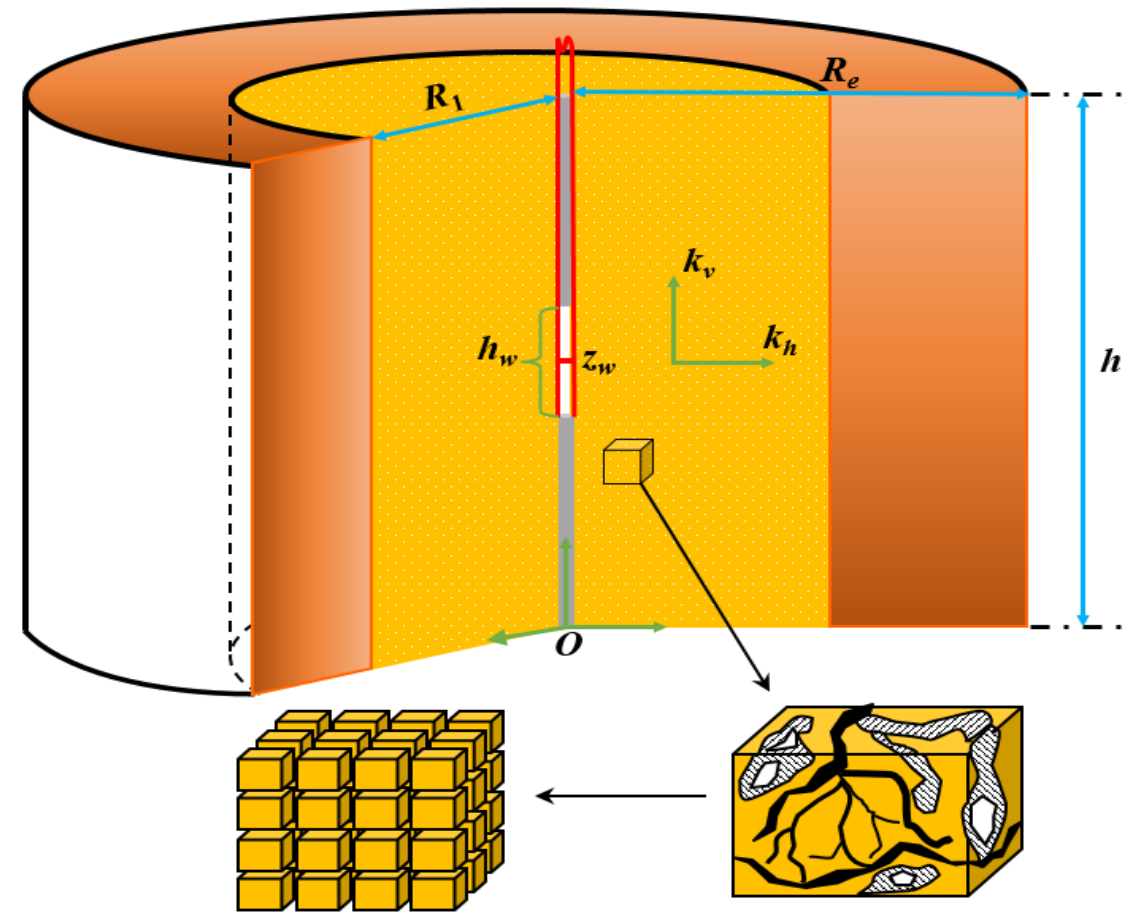

Figure 2. A schematic of partially penetrated well in composite naturally fractured gas reservoir. 


\subsection{Model Solution}

Based on the assumptions described in Section 2.2, the dimensionless governing equations can be established and the detailed derivation is presented in Appendix A. As shown in Appendix B, by the Laplace transforms with respect to $t_{\mathrm{D}}$ and the finite Fourier cosine transforms with respect to $z_{\mathrm{D}}$, the line source solution for dimensionless bottom-hole pressure is obtained as following:

$$
\widetilde{s}_{w D}=\frac{1}{q_{0}}\left[\frac{E_{0} I_{0}\left(r_{D} q_{0}\right)+F_{0} K_{0}\left(r_{D} q_{0}\right)}{F_{0} K_{1}\left(q_{0}\right)-E_{0} I_{1}\left(q_{0}\right)}\right]+2 \sum_{n=1}^{\infty} \frac{\sin ^{2}\left(\frac{1}{2} u_{n} h_{w D}\right)}{\left(\frac{1}{2} u_{n} h_{w D}\right)^{2}} \frac{1}{q_{n}}\left[\frac{E_{n} I_{0}\left(r_{D} q_{n}\right)+F_{n} K_{0}\left(r_{D} q_{n}\right)}{F_{n} K_{1}\left(q_{n}\right)-E_{n} I_{1}\left(q_{n}\right)}\right] \cos ^{2}\left(u_{n} z_{w D}\right)
$$

where, $s$ is the time variable in Laplace domain, and the expressions of $E_{n}, F_{n}, G_{n}, H_{n}, q_{n}, T_{n}, f(s)$ are as following:

$$
\begin{gathered}
E_{n}=q_{n} G_{n} K_{1}\left(R_{1 D} q_{n}\right)+M T_{n} H_{n} K_{0}\left(R_{1 D} q_{n}\right) \\
F_{n}=q_{n} G_{n} I_{1}\left(R_{1 D} q_{n}\right)-M T_{n} H_{n} I_{0}\left(R_{1 D} q_{n}\right) \\
G_{n}=\frac{K_{1}\left(R_{e D} T_{n}\right)}{I_{1}\left(R_{e D} T_{n}\right)} I_{0}\left(R_{1 D} T_{n}\right)+K_{0}\left(R_{1 D} T_{n}\right) \\
H_{n}=\frac{K_{1}\left(R_{e D} T_{n}\right)}{I_{1}\left(R_{e D} T_{n}\right)} I_{1}\left(R_{1 D} T_{n}\right)-K_{1}\left(R_{1 D} T_{n}\right) \\
q_{n}=\sqrt{s f(s)+\frac{u_{n}^{2}}{h_{1 D}^{2}}} \\
T_{n}=\sqrt{\frac{s}{\sigma}+\frac{u_{n}^{2}}{h_{2 D}^{2}}} \\
f(s)=\frac{\lambda+\sqrt{\kappa_{1}} \omega(1-\omega) s}{\lambda+\sqrt{\kappa_{1}}(1-\omega) s}
\end{gathered}
$$

As shown above, $f(s)$ for the pseudosteady-state matrix-fracture mass exchange is slightly different from the expression of Warren-Root's model [44] due to the consideration of anisotropy. It is noticed that if $\kappa_{1}$ equals to 1 , the expression of $f(s)$ simplifies to the same form as isotropic dual-porosity mediums:

$$
f(s)=\frac{\lambda+\omega(1-\omega) s}{\lambda+(1-\omega) s}
$$

On the basis of superposition principle [45], the relationship between the dimensionless bottom-hole pseudopressure solution at a fixed constant rate inner boundary and the dimensionless flow rate solution at a fixed bottom-hole pressure can be written as:

$$
\widetilde{q}_{w D}=\frac{\tilde{p}_{w D}}{s^{2}}
$$

With a numerical Laplace inversion algorithm proposed by Stehfest [46], the solution of dimensionless production rate in real time domain can be obtained, and the dimensional production rate can be calculated based on the following equation:

$$
q_{g}=q_{w D} \frac{k_{f h i} h\left[p_{p}\left(p_{i}\right)-p_{p}\left(p_{w f}\right)\right]}{\alpha_{p} \mu_{g i} B_{g i}}
$$

where, $q_{g}$ denotes production rate; $k_{f h i}$ denotes horizontal fracture permeability at initial reservoir pressure; $\alpha_{p}$ is the unit conversion coefficient. 


\section{Model Verification}

Since there is no relevant literature on partially penetrated well in composite naturally fractured gas reservoir, to validate the accuracy of the proposed model, the comparison of this model with an analytical solution of completely penetrated well in composite reservoir is implemented.

Although Prado and Da [10] mainly aimed at analyzing transient pressure, the dimensionless production rate solution can also be obtained based on the relationship of Equation (14). Therefore, we consider the circumstance of $h_{\mathrm{w}}=h$ in our model, which means the well is penetrated completely. We compare the results obtained from our model with Prado and Da's. The dimensionless parameters used for validation are presented in Table 1. All of the dimensionless parameters are defined in Appendix A.

Table 1. The dimensionless parameters for model validation.

\begin{tabular}{cc}
\hline Parameters & Value \\
\hline Dimensionless reservoir radius, $R_{\mathrm{eD}}$ & 6000 \\
Dimension inner region radius, $R_{1 \mathrm{D}}$ & 2000 \\
Dimensionless reservoir thickness, $h_{D}$ & 300 \\
Storativity ratio of natural fracture, $\omega$ & 0.05 \\
Interporosity flow coefficient between fractures and matrix, $\lambda$ & 0.0001 \\
Mobility ratio between outer and inner regions, $M$ & 0.025 \\
Diffusivity ration between outer and inner regions, $\delta$ & 0.05 \\
Permeability anisotropy factor for fracture, $\kappa_{1}$ & 1 \\
Permeability anisotropy factor for matrix in outer region, $\kappa_{2}$ & 1 \\
\hline
\end{tabular}

Figure 3 shows the comparison of production rate curves. The lines represent the results obtained from the proposed model, and the dots represent the results obtained from Prado and Da's method. As we can see, there is a good agreement between these two models, which indicates that our proposed model for partially penetrated well in composite naturally fractured reservoir is accurate.

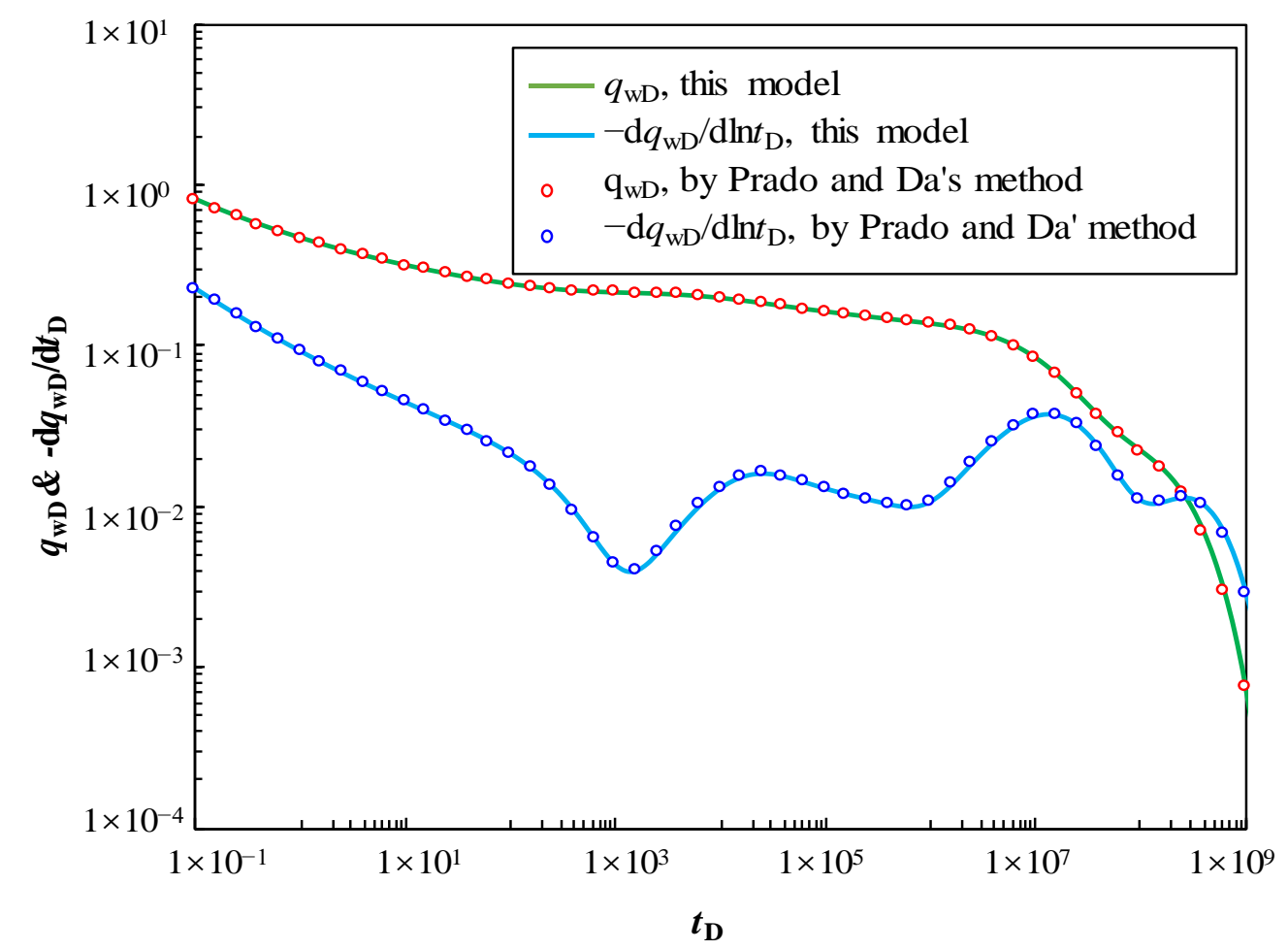

Figure 3. A comparison of the dimensionless production rate curves between this model and literature's method. 


\section{Parameters Sensitivity Analysis}

Relevant parameters used to conduct sensitivity analysis are presented in Table 2.

Table 2. The reservoir, fluid, and well parameters for sensitivity analysis.

\begin{tabular}{cc}
\hline Parameters & Value \\
\hline Reservoir temperature, $\mathrm{T}(\mathrm{K})$ & 350 \\
Initial reservoir pressure, $p_{i}(\mathrm{MPa})$ & 45 \\
Inner region radius, $R_{1}(\mathrm{~m})$ & $100,200,300,400$ \\
Reservoir radius, $R_{e}(\mathrm{~m})$ & 800 \\
Reservoir thickness, $h(\mathrm{~m})$ & 30 \\
Well perforation height, $h_{\mathrm{w}}(\mathrm{m})$ & $5,10,15,20$ \\
Initial fracture horizontal permeability, $k_{\mathrm{fhi}}\left(10^{-3} \mu \mathrm{m}^{2}\right)$ & 1.5 \\
Initial matrix horizontal permeability, $k_{\mathrm{m} 2 \mathrm{hi}}\left(10^{-3} \mu \mathrm{m}^{2}\right)$ & 0.2 \\
Interporosity flow coefficient between fracture and matrix, $\lambda$ & 0.01 \\
Storativity ratio of natural fracture, $\omega$ & 0.05 \\
Mobility ratio between outer and inner regions, $M$ & $0.1,0.2,0.3,0.4$ \\
Diffusivity ratio between outer and inner regions, $\delta$ & 0.05 \\
Permeability anisotropy factor for fracture, $\kappa_{1}$ & $1,10,100,1000$ \\
Permeability anisotropy factor for matrix in outer region, $\kappa_{2}$ & 20 \\
Permeability stress-sensitivity coefficient, $\gamma_{k}\left(\mathrm{MPa}{ }^{-1}\right)$ & $0.01,0.03,0.05,0.07$ \\
Specific gravity, $\gamma_{\mathrm{g}}$ & 0.6 \\
Critical pressure, $p_{\mathrm{c}}(\mathrm{MPa})$ & 5 \\
Critical temperature, $T_{\mathrm{c}}(\mathrm{K})$ & 195 \\
Wellbore radius, $r_{\mathrm{w}}(\mathrm{m})$ & 0.1 \\
Well bottom-hole pressure, $p_{\mathrm{wf}}(\mathrm{MPa})$ & 30 \\
\hline
\end{tabular}

\subsection{Inner Region Radius}

Figure 4 shows the rate decline curves and cumulative production curves for four different values of inner region radius under constant bottom-hole pressure. It can be seen from Figure 4 that the inner region radius has an obvious effect on the production performance. Due to the high permeability of the naturally fractured inner region, the production rate is higher at the larger inner region size in the initial stage. Nevertheless, the rate decreases rapidly after 700 days. This is mainly because the gas reserves in the inner region have been produced to a large extent, for cases with larger inner region radius, the outer region radius is smaller, leading to reduced gas reserves. Figure 5 illustrates the evolution of pseudotime with respect to production time, which embodies the degree of deviation from liquid flow behavior.

\subsection{Mobility Ratio Between Outer and Inner Regions}

Figures 6 and 7 present the impact of mobility ratio between outer and inner region regions on the production performance curves and pseudotime factor respectively. In these scenarios, we keep the fracture permeability $k_{\mathrm{fh}}$ the same while changing the value of $k_{\mathrm{m} 2 \mathrm{~h}}$ in order to create different mobility ratio. It can be seen that with all other parameters kept constant, the production curves and pseudotime curves exhibit similar characteristics as in Figures 4 and 5. The larger the value of $M$, the higher production rate, as $M$ reflects the flow capacity of region 2 compared to region 1 . Thus, there will be more supplement into region 1 to hold a high production rate when $M$ is bigger. With the increase of mobility ratio, the diffusivity ratio between the outer and inner regions will also increase, and the pressure wave propagates faster, which leads to a notable decrease of pseudotime factor. 


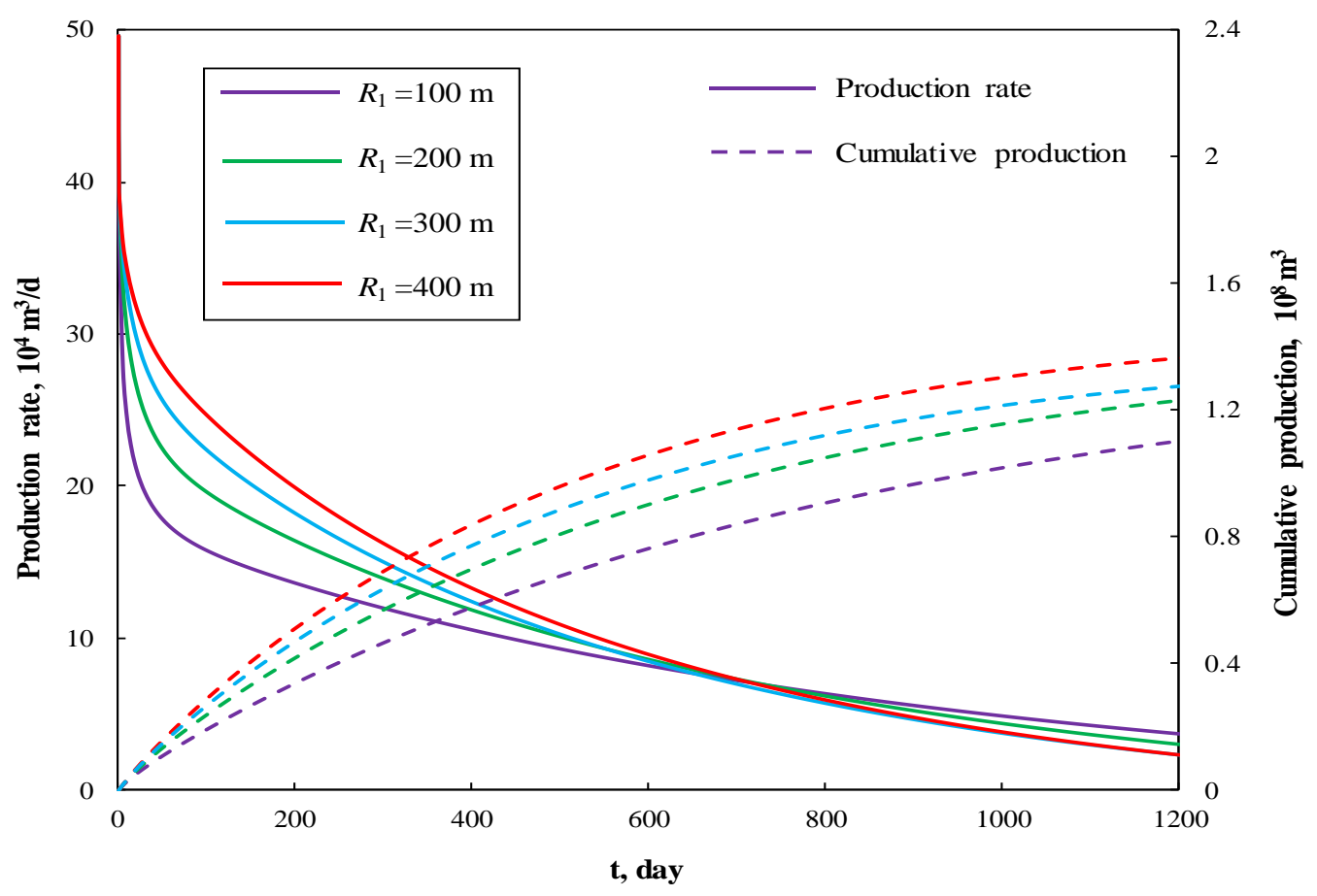

Figure 4. The effect of inner region radius on production performance curves.

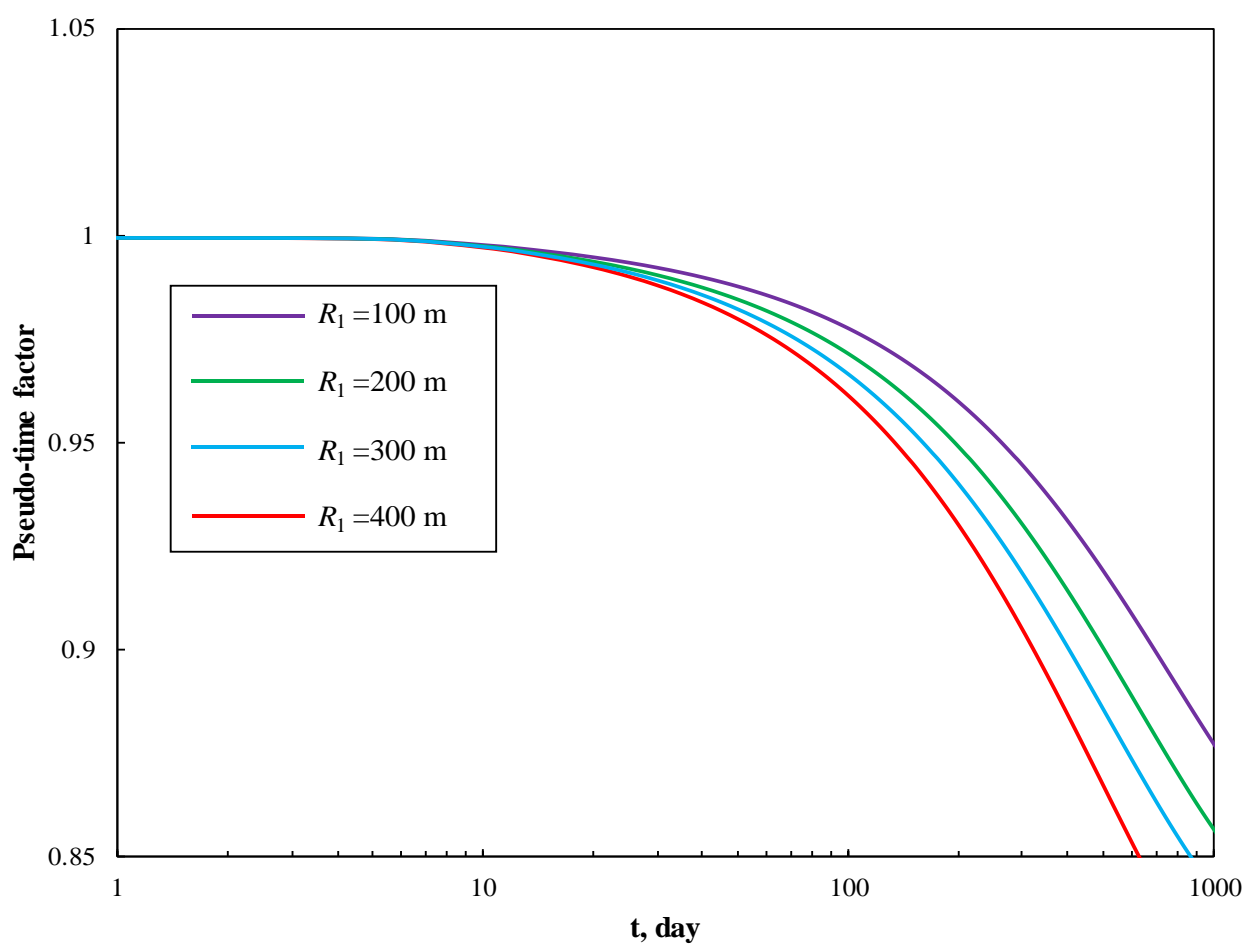

Figure 5. The effect of inner region radius on pseudotime factor. 


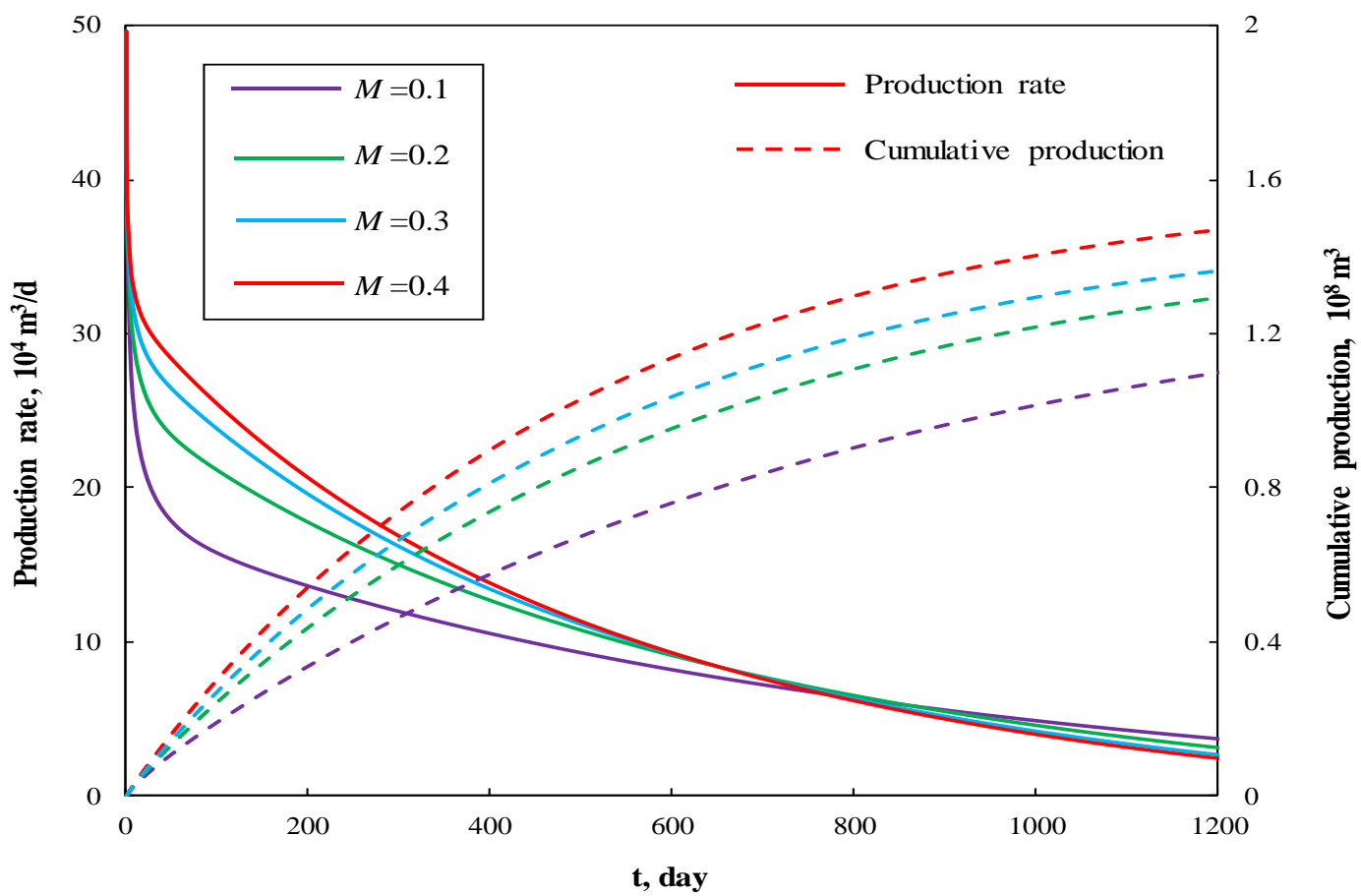

Figure 6. The effect of mobility ratio on production performance curves.

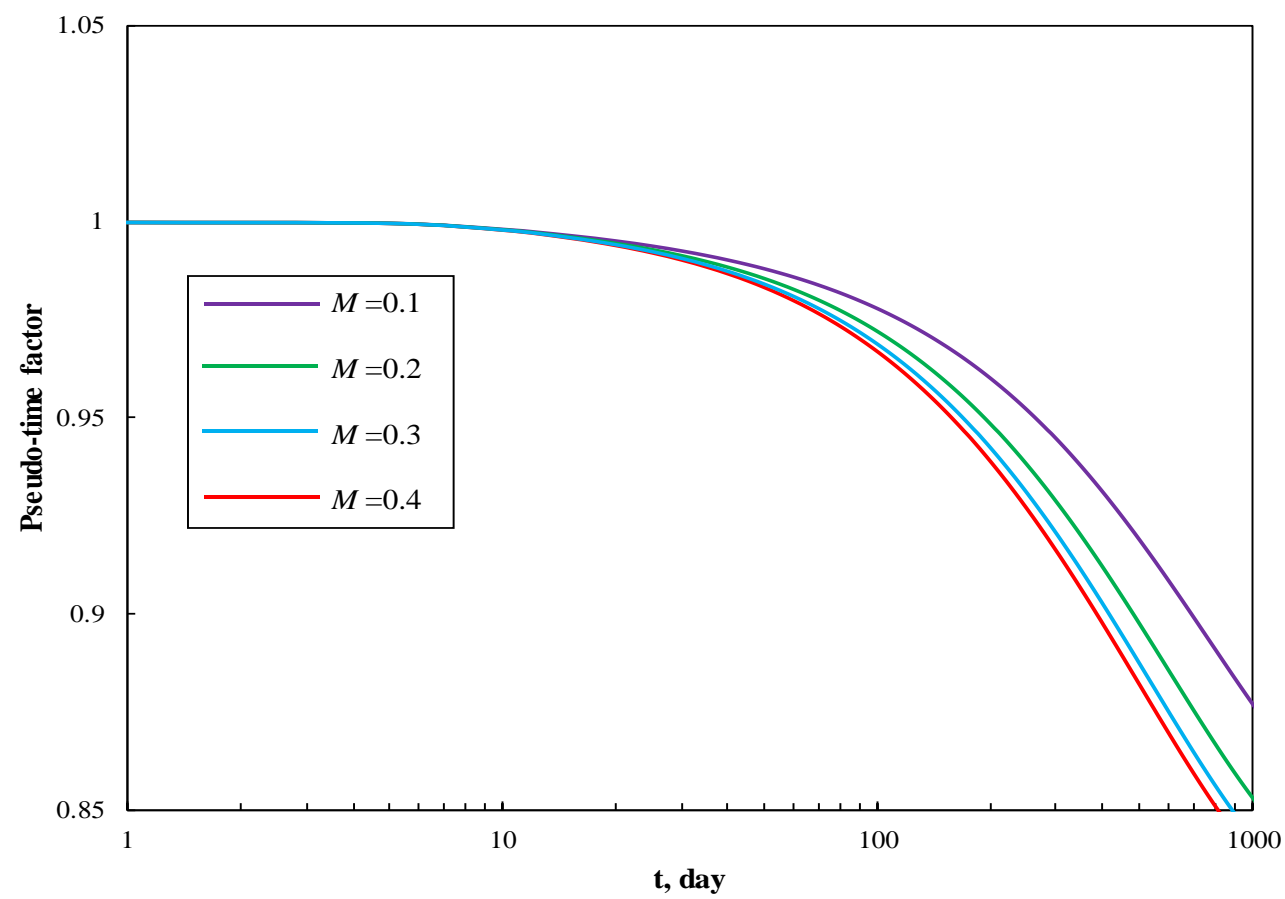

Figure 7. The effect of mobility ratio on pseudotime factor.

\subsection{Fracture Permeability Anisotropy Factor}

Figures 8 and 9 display the effect of fracture permeability anisotropy factor on production performance curves and pseudotime factor respectively. It is worth noting that fracture permeability anisotropy factor mainly affects production rate in the early stage. The increase of anisotropy factor causes the slightly decrease of production rate. In late stage, the effect of $\kappa_{1}$ is weak. 


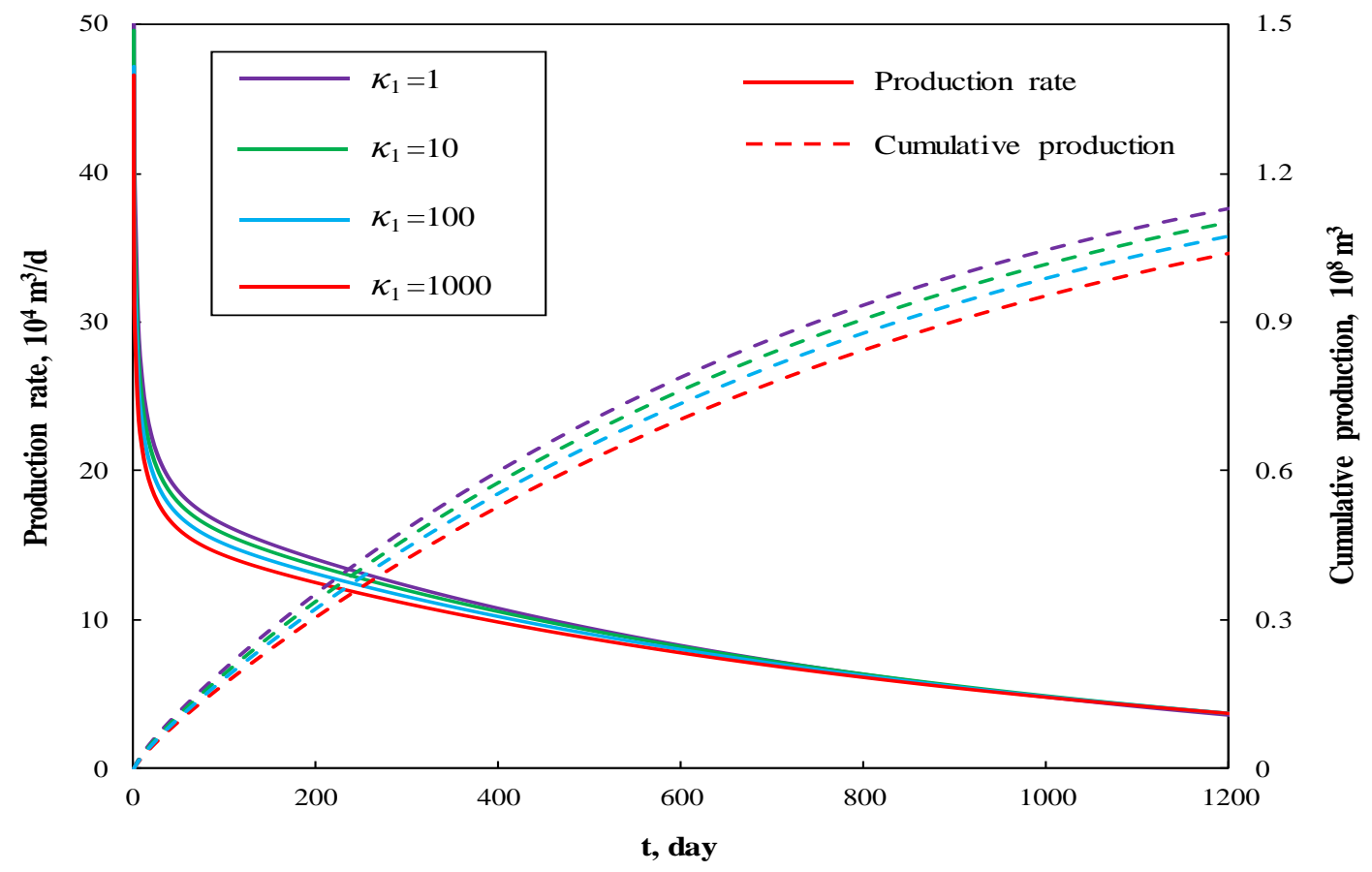

Figure 8. The effect of fracture permeability anisotropy factor on production performance curves.

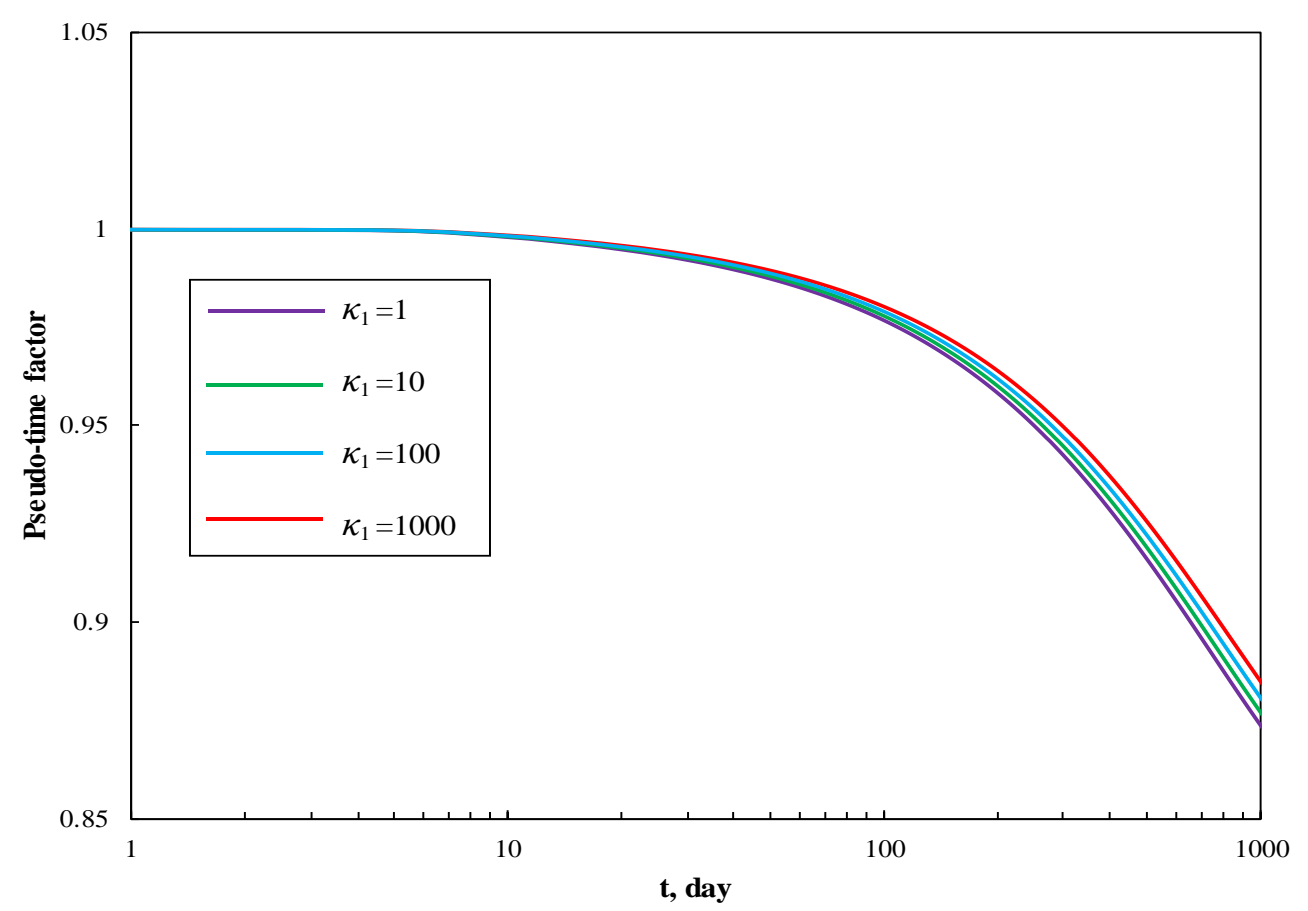

Figure 9. The effect of fracture permeability anisotropy factor on pseudotime factor.

\subsection{Permeability Stress-Sensitivity Coefficient}

Figures 10 and 11 depict the effect of permeability stress-sensitivity coefficient on production performance curves and pseudotime factor respectively. For larger stress-sensitivity coefficient, there will be a rapid rate decline and smaller cumulative production. This is because that stress sensitivity decreases the permeability of natural fracture and increases flowing resistance. With the increase of stress-sensitivity coefficient, the pseudotime factor will decrease, which means the formation energy depletes faster. 


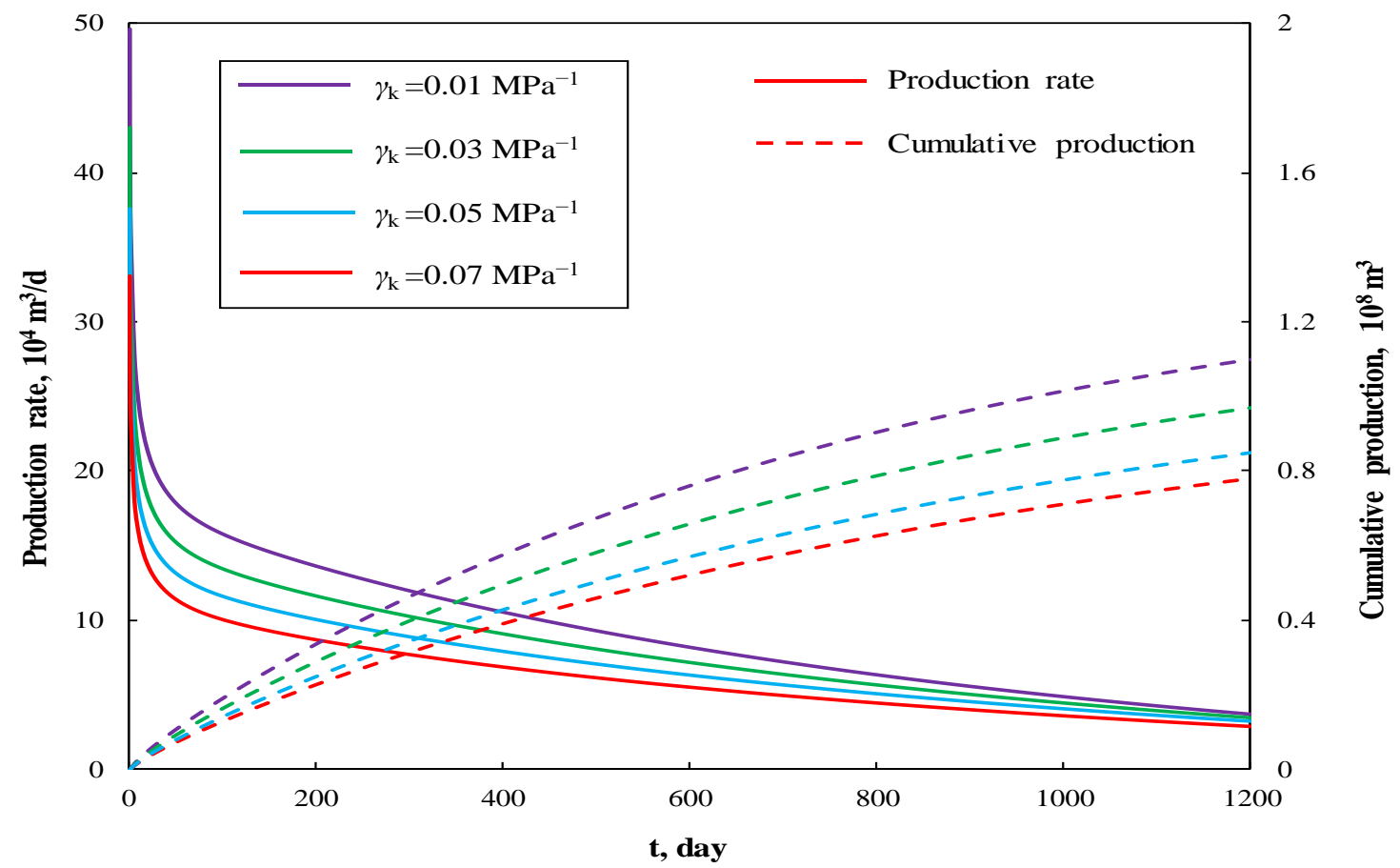

Figure 10. The effect of stress-sensitivity coefficient on production performance curves.

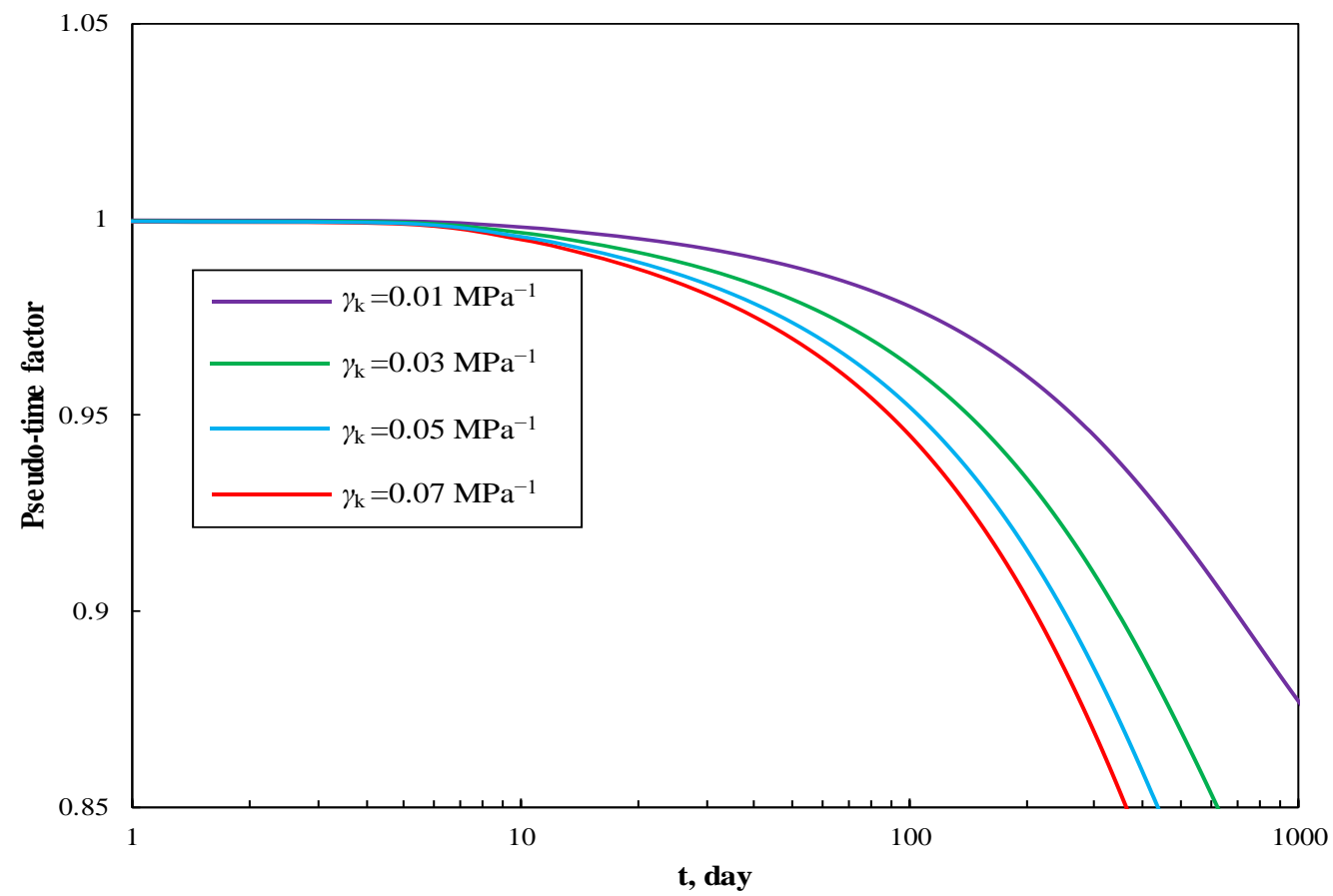

Figure 11. The effect of stress-sensitivity coefficient on pseudotime factor.

\subsection{Well Perforation Height}

Figures 12 and 13 show the effect of well perforation height on production performance curves and pseudotime factor respectively. As we know, the perforation height determines the area of wellbore into which fluid flows. The smaller the $h_{\mathrm{w}}$, the bigger pressure drop and flow resistance. Thus, the small perforation height leads to low production rate, and slow formation energy depletion as depicted in Figure 13. It is desirable to improve perforation height in premise of avoiding water encroachment. 


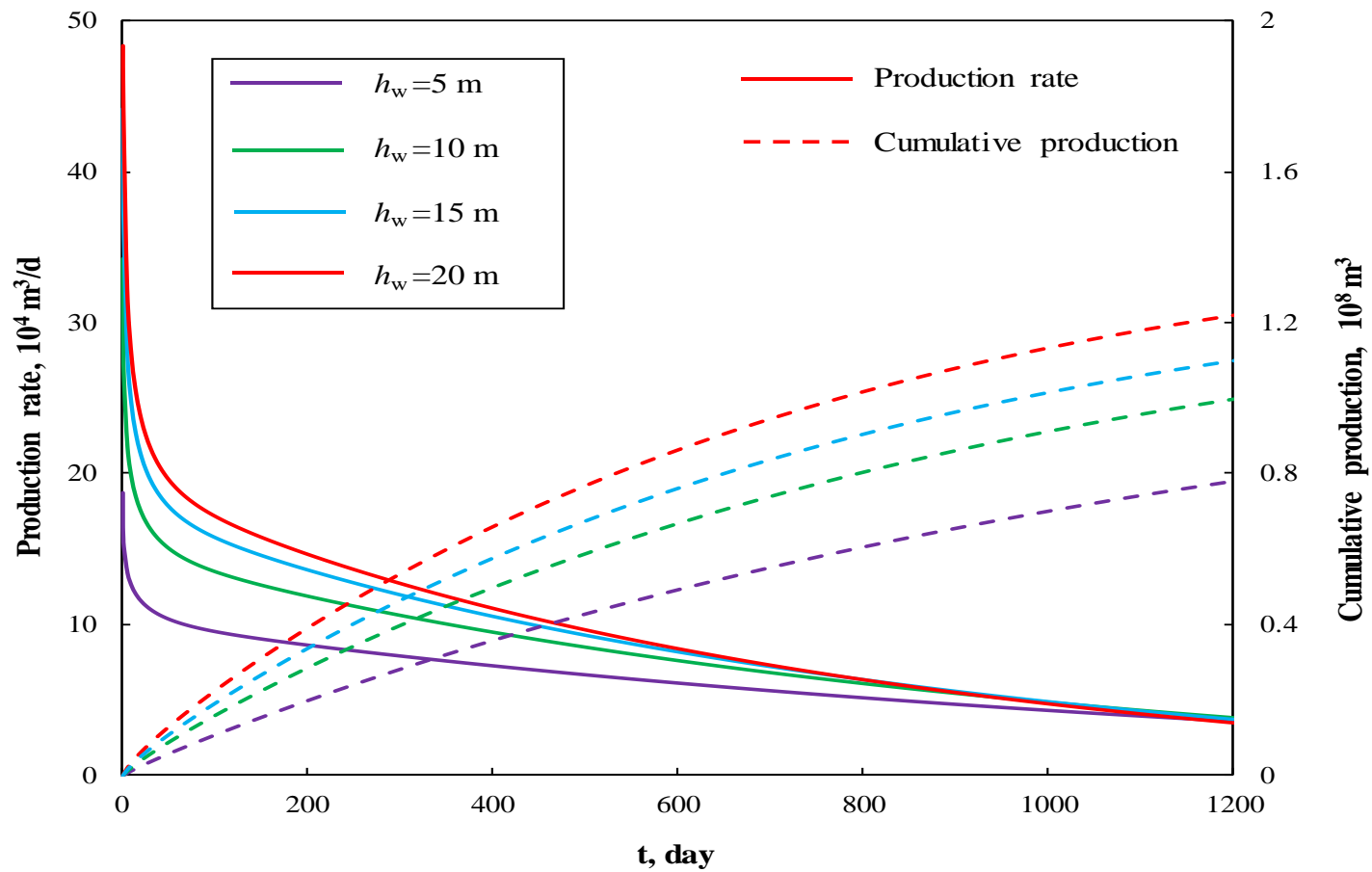

Figure 12. The effect of well perforation height on production performance curves.

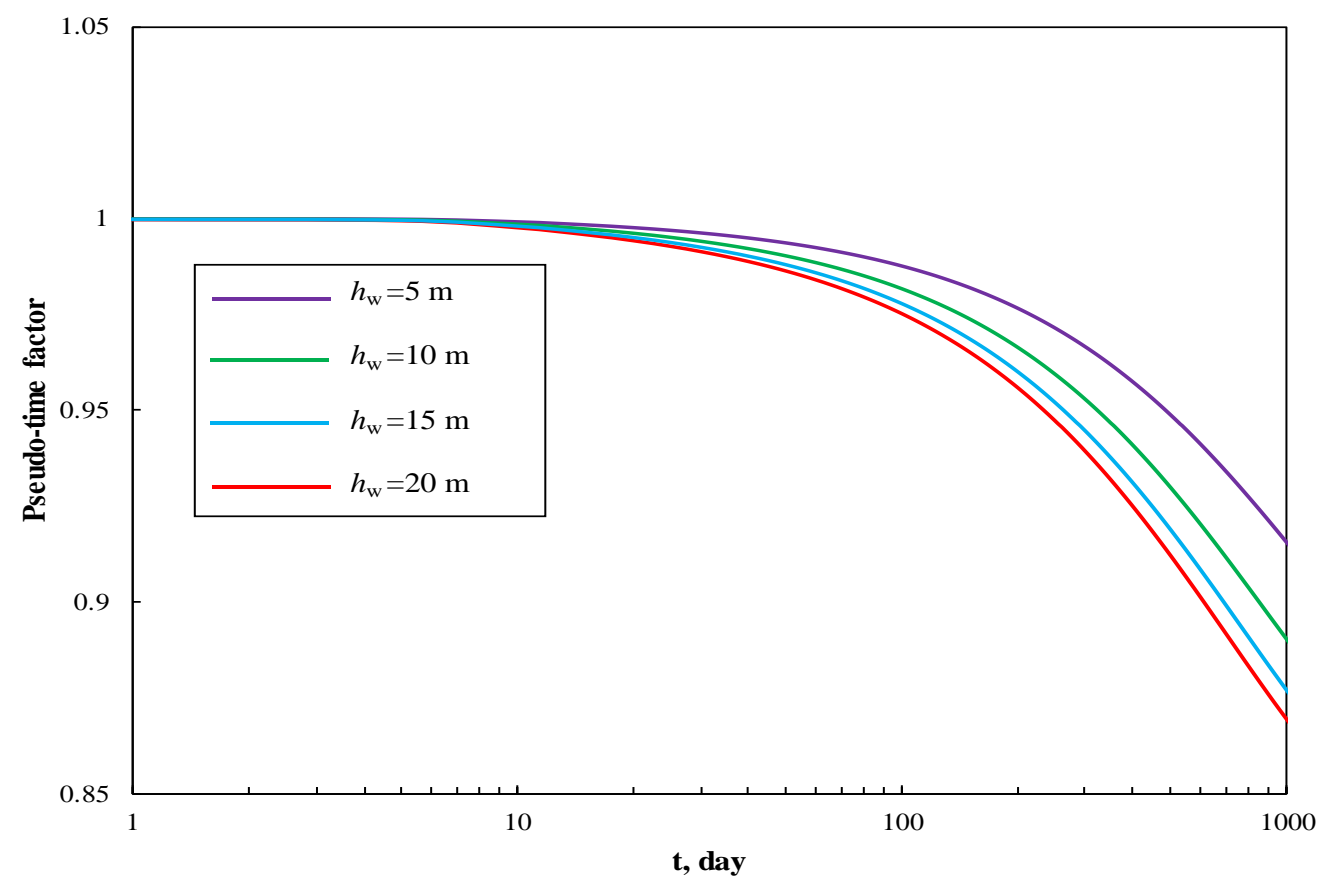

Figure 13. The effect of well perforation height on pseudotime factor.

\section{Field Data Matching}

In order to prove the practical application of the proposed model, the production data of an actual case from Moxi gas field in Sichuan Basin was used. The well was partially penetrated and a schedule of constant well bottom-hole pressure was adopted at the initial production stage. Thus, the gas flow rate was characterized by a decreasing trend for a long time. The following equation was used to describe the relationship between porosity and reservoir pressure: 


$$
\varphi=\varphi_{i} e^{-c_{\varphi}\left(p_{i}-p\right)}
$$

where, $\varphi_{i}$ and $\varphi$ denote porosity at initial and current reservoir pressure, respectively, following Equation (3); $c_{\varphi}$ denotes formation compressibility, and it can be calculated by the following equation:

$$
c_{\varphi}=\frac{\varphi_{m} c_{m}+\varphi_{f} c_{f}}{\varphi_{m}+\varphi_{f}}
$$

where, $c_{m}$ and $c_{f}$ denote matrix and fracture system compressibility, respectively, following Equation (4); $\varphi_{m}$ and $\varphi_{f}$ denote matrix and fracture system compressibility, respectively.

All input parameters are listed in Table 3. Figure 14 illustrates a comparison between the field production rate data and the matching results obtained from the proposed model. In Figure 14, the solid line represents the matching result considering formation compressibility. The dash line represents the matching result not considering formation compressibility. That is, the formation compressibility equals to zero and the porosity is constant. As we can see from Figure 14, the real field data represented by the red circles is in good agreement with the result considering formation compressibility. The matching data is not good for the model without considering formation compressibility at late time. Therefore, it is necessary to consider formation compressibility and porosity stress-sensitivity in abnormally high-pressure gas reservoir production performance analysis.

Table 3. The reservoir, fluid, and well parameters of the real gas field.

\begin{tabular}{cc} 
Parameters & Value (Field Case) \\
\hline Reservoir temperature, $\mathrm{T}(\mathrm{K})$ & 347 \\
Initial reservoir pressure, $p_{i}(\mathrm{MPa})$ & 48.6 \\
Inner region radius, $R_{1}(\mathrm{~m})$ & 102 \\
Reservoir radius, $R_{e}(\mathrm{~m})$ & 783 \\
Reservoir thickness, $h(\mathrm{~m})$ & 32 \\
Formation compressibility, $c_{\varphi}\left(\mathrm{MPa}^{-1}\right)$ & 0.001 \\
Initial fracture horizontal permeability, $k_{\mathrm{fhi}}\left(10^{-3} \mu \mathrm{m}^{2}\right)$ & 1.097 \\
Initial matrix horizontal permeability, $k_{\mathrm{m} 2 \mathrm{hi}}\left(10^{-3} \mu \mathrm{m}^{2}\right)$ & 0.2 \\
Interporosity flow coefficient between fracture and $\mathrm{matrix}_{1} \lambda$ & 0.01 \\
Storativity ratio of natural fracture, $\omega$ & 0.05 \\
Mobility ratio between outer and inner regions, $M$ & 0.18 \\
Diffusivity ratio between outer and inner regions, $\delta$ & 0.05 \\
Permeability anisotropy factor for fracture, $\kappa_{1}$ & 36 \\
Permeability anisotropy factor for matrix in outer region, $\kappa_{2}$ & 20 \\
Permeability stress-sensitivity coefficient, $\gamma_{k}\left(\mathrm{MPa}^{-1}\right)$ & 0.01 \\
Specific gravity, $\gamma_{\mathrm{g}}$ & 0.596 \\
Critical pressure, $p_{\mathrm{c}}(\mathrm{MPa})$ & 4.67 \\
Critical temperature, $T_{\mathrm{c}}(\mathrm{K})$ & 195.12 \\
Wellbore radius, $r_{\mathrm{w}}(\mathrm{m})$ & 0.1 \\
Well bottom-hole pressure, $p_{\mathrm{wf}}(\mathrm{MPa})$ & 31 \\
\hline
\end{tabular}




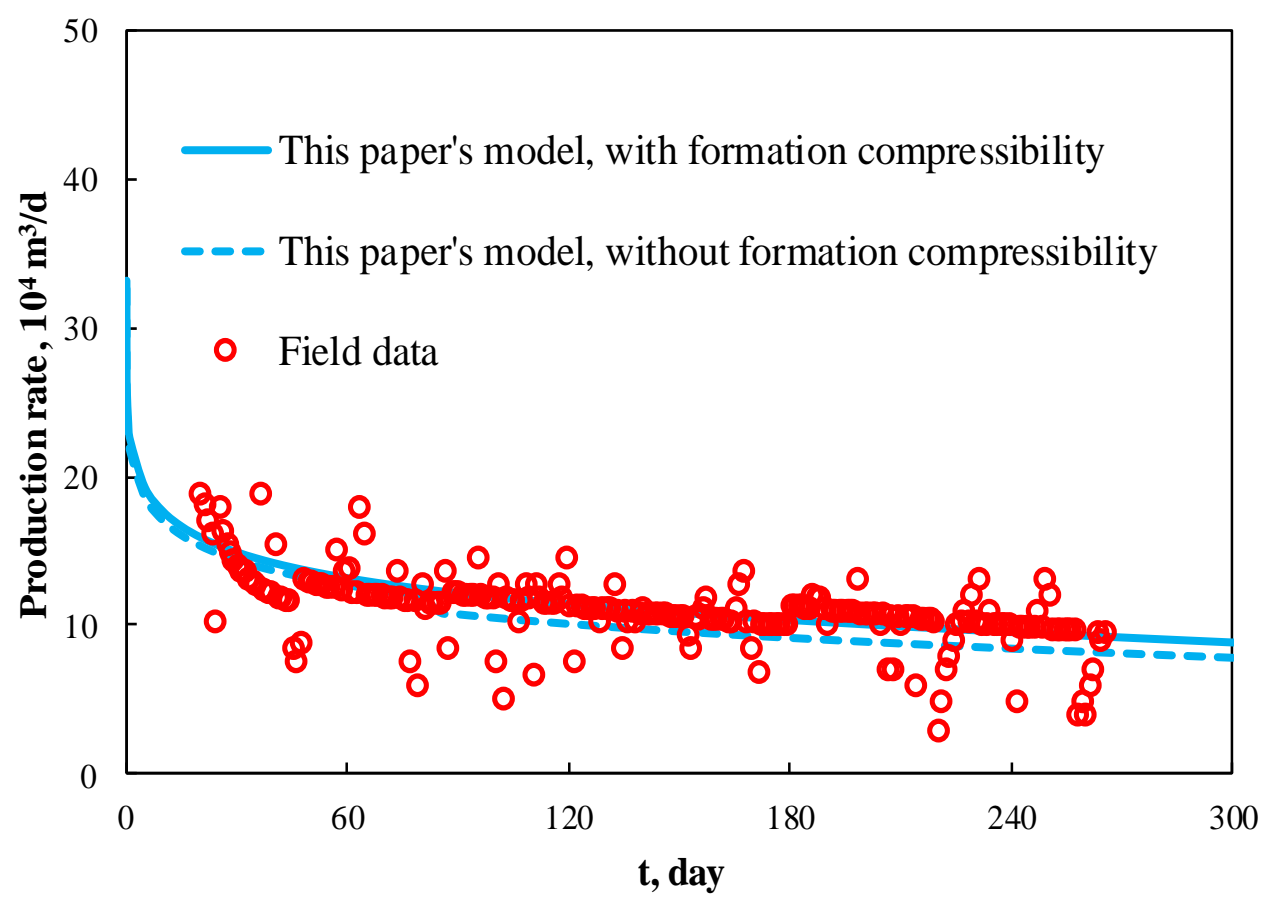

Figure 14. A comparison of the production rate data between field data and the proposed model.

\section{Conclusions}

Through the modified definition of pseudopressure and pseudotime factor, the 2D diffusivity equations of gas flow in abnormally high-pressured composite naturally fractured reservoirs are established. The semianalytical solution was obtained by the utility of Laplace and finite Fourier cosine transforms. The presented model can account for the pressure-dependent fluid and rock properties, permeability anisotropy, and limited-entry well phenomena. Real gas field data matching demonstrates that the proposed model has good applicability. Based on this work, the following conclusions can be drawn:

(1) Porosity stress-sensitivity is considered due to the high formation energy in abnormally high-pressured reservoirs and the classical Warren-Root model is improved to account for permeability anisotropy.

(2) The inner region radius and mobility ratio between outer and inner region exhibit the same characteristics of the effect on production performance. Larger the value of them, the higher production rate at initial stage while rapid reduction in late stage due to weak supplement.

(3) The fracture permeability anisotropy factor mainly affects production rate in early stage. In late stage, the effect of it is small. Permeability stress-sensitivity has a notably negative effect on production rate. To avoid the rapid decrease of fracture permeability, reasonable well bottom-hole pressure should be set up in field.

Author Contributions: Conceptualization, M.W. and X.W.; methodology, X.W.; software, W.Z.; validation, L.Z., M.S. and H.Z.; formal analysis, X.W.; investigation, M.W.; resources, W.Z.; data curation, M.W.; writing-original draft preparation, M.W.; writing—review and editing, M.W.; visualization, X.W.; supervision, W.Z.; project administration, X.M.; funding acquisition, X.W.

Funding: This work was supported by the Fundamental Research Funds for the Central Universities (Grant No. 2652018243).

Conflicts of Interest: The authors declare no conflict of interest. 


\section{Nomenclature}

$B_{g} \quad$ Gas formation volume factor, $\mathrm{m}^{3} / \mathrm{m}^{3}$

$B_{g i} \quad$ Initial gas formation volume factor, $\mathrm{m}^{3} / \mathrm{m}^{3}$

$c_{g} \quad$ Gas compressibility, $\mathrm{MPa}^{-1}$

$c_{g i} \quad$ Initial gas compressibility, $\mathrm{MPa}^{-1}$

$c_{f} \quad$ Fracture compressibility, $\mathrm{MPa}^{-1}$

$c_{m} \quad$ Matrix rock compressibility, $\mathrm{MPa}^{-1}$

$c_{\varphi} \quad$ Formation compressibility, $\mathrm{MPa}^{-1}$

$G_{p} \quad$ Cumulative production, $10^{8} \mathrm{~m}^{3}$

$G_{s c} \quad$ Original gas in place, $10^{8} \mathrm{~m}^{3}$

$h \quad$ Formation height, $\mathrm{m}$

$K_{f} \quad$ Equivalent permeability for fracture, $10^{-3} \mu \mathrm{m}^{2}\left(10^{-3} \mu \mathrm{m}^{2}=1 \mathrm{mD}\right)$

$K_{m 1}$ Equivalent permeability for matrix in inner region, $10^{-3} \mu \mathrm{m} 2$

$k_{f h} \quad$ Horizontal permeability of fracture, $10^{-3} \mu \mathrm{m}^{2}$

$k_{f o} \quad$ Vertical permeability of fracture, $10^{-3} \mu \mathrm{m}^{2}$

$k_{m 1 h} \quad$ Horizontal permeability of matrix in inner region, $10^{-3} \mu \mathrm{m}^{2}$

$k_{m 1 v}$ Vertical permeability of matrix in inner region, $10^{-3} \mu \mathrm{m}^{2}$

$k_{m 2 h} \quad$ Horizontal permeability of matrix in outer region, $10^{-3} \mu \mathrm{m}^{2}$

$k_{m 2 v}$ Vertical permeability of matrix in outer region, $10^{-3} \mu \mathrm{m}^{2}$

$M \quad$ Mobility ratio between outer and inner regions, dimensionless

$p_{w D} \quad$ Dimensionless wellbore pressure, dimensionless

$p_{p} \quad$ Pseudopressure, $\mathrm{MPa}$

$q_{g} \quad$ Production rate, $10^{4} \mathrm{~m}^{3} / \mathrm{d}$

$r_{w} \quad$ Wellbore radius, $\mathrm{m}$

$R_{e} \quad$ Reservoir radius, $\mathrm{m}$

$R_{1} \quad$ Inner region radius, $\mathrm{m}$

$s \quad$ Time variable in Laplace domain, dimensionless

$T$ Temperature, $\mathrm{K}$

$\mathrm{Z} \quad$ Gas deviation factor, dimensionless

Greek Letters

$\alpha \quad$ Shape factor of matrix, $1 / \mathrm{m}^{2}$

$\alpha_{p} \quad$ Unit conversion coefficient, $3.6 \times 24 \times 2 \pi \times 10^{-7}$

$\alpha_{t} \quad$ Unit conversion coefficient, $3.6 \times 24 \times 10^{-3}$

$\beta \quad$ Pseudo-time factor, dimensionless

$\gamma_{k} \quad$ Permeability stress-sensitivity coefficient, $\mathrm{MPa}^{-1}$

$\gamma_{g} \quad$ Gas specific gravity, dimensionless

$\delta \quad$ Diffusivity ratio between outer and inner regions, dimensionless

$\kappa_{1} \quad$ Permeability anisotropy factor for fracture, dimensionless

$\kappa_{2}$ Permeability anisotropy factor for matrix in outer region, dimensionless

$\lambda$ Interporosity flow coefficient between fractures and matrix, dimensionless

$\mu_{g} \quad$ Gas viscosity, $10^{-3}$ Pa $\bullet$

$\rho_{g} \quad$ Gas density, $10^{3} \mathrm{~kg} / \mathrm{m}^{3}$

$\varphi \quad$ Porosity, fraction

$\varphi_{f} \quad$ Fracture system porosity, fraction

$\varphi_{m} \quad$ Matrix system porosity, fraction

$\omega \quad$ Storativity ratio of natural fracture, dimensionless

Special Functions

$I_{0} \quad$ Modified Bessel function of the first kind, zero order

$I_{1} \quad$ Modified Bessel function of the first kind, first order

$K_{0} \quad$ Modified Bessel function of the second kind, zero order

$K_{1} \quad$ Modified Bessel function of the second kind, first order 


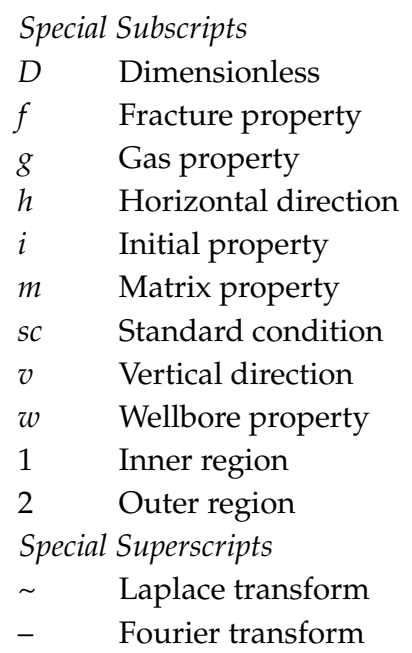

\section{Appendix A. Derivation of the Mathematical Model}

Based on the mass conservation principle, Darcy's law and real gas equation of state, the governing equations under isothermal circumstance can be obtained respectively. In the inner region, flow conductivity of fracture is greatly higher than matrix, and the double porosity/single permeability model is employed.

Natural fracture:

$$
\frac{1}{r} \frac{\partial}{\partial r}\left(r \frac{\partial p_{p f}}{\partial r}\right)+\frac{\partial}{\partial z}\left(\frac{k_{f v}}{k_{f h}} \frac{\partial p_{p f}}{\partial z}\right)=\frac{\varphi \mu_{g} c_{t}}{\alpha_{t} k_{f h}} \frac{\partial p_{p f}}{\partial t}-\alpha \frac{K_{m 1}}{K_{f}} \frac{K_{f}}{k_{f h}}\left(p_{p m}-p_{p f}\right)
$$

Matrix:

$$
\alpha \frac{K_{m 1}}{K_{f}}\left(p_{p m}-p_{p f}\right)+\frac{\left(\varphi c_{t}\right)_{m}}{\left(\varphi c_{t}\right)_{f}} \frac{k_{f h}}{K_{f}} \frac{\mu_{g}\left(\varphi c_{t}\right)_{f}}{k_{f h}} \frac{\partial p_{p m}}{\partial t}=0
$$

where, $K_{m 1}$ and $K_{f}$ are equivalent permeability for matrix and fracture in inner region. As a consequence of anisotropy, the equivalent permeability defined in the following equation can reflect the flowing capacity for fluid mass transfer between matrix and fracture comprehensively.

$$
K_{m 1}=\sqrt{k_{m 1 v} k_{m 1 h}}, K_{f}=\sqrt{k_{f v} k_{f h}}
$$

The pseudopressure functions are defined as:

$$
p_{p f}=\frac{\mu_{g i} Z_{i}}{k_{f h i} p_{i}} \int_{p_{s c}}^{p_{f}} \frac{k_{f h} p}{\mu_{g} Z} d p, p_{p m 1}=\frac{\mu_{g i} Z_{i}}{k_{f h i} p_{i}} \int_{p_{s c}}^{p_{m 1}} \frac{k_{f h} p}{\mu_{g} Z} d p .
$$

In Equations (A1) and (A2), the viscosity, compressibility of gas, and the permeability of fracture change with reservoir pressure, hence change with time. Thus, the control equations are still nonlinear. To linearize the control equations, the pseudotime factor can be defined as:

$$
\beta=\frac{1}{t} \frac{\phi_{i} c_{t i} \mu_{g i}}{k_{f h i}} \int_{0}^{t} \frac{k_{f h}}{\phi c_{t} \mu_{g}} d t
$$

To simplify the governing equations during the derivation, we assume that the following approximate equation is tenable.

$$
\frac{\left(\phi c_{t}\right)_{m}}{\left(\phi c_{t}\right)_{f}} \approx \frac{\left(\phi c_{t}\right)_{m i}}{\left(\phi c_{t}\right)_{f i}}
$$


Based on Equation (A5), the control equations can be further transformed as following:

$$
\begin{gathered}
\alpha \frac{K_{m 1}}{K_{f}}\left(p_{p m 1}-p_{p f}\right)+\sqrt{\kappa_{1}} \frac{\left(\phi c_{t}\right)_{m 1 i}}{\left(\phi c_{t}\right)_{f i}} \frac{\mu_{g i}\left(\phi c_{t}\right)_{f i}}{k_{f h i}} \frac{\partial p_{p m 1}}{\partial(\beta t)}=0 \\
\alpha \frac{K_{m 1}}{K_{f}}\left(p_{p m 1}-p_{p f}\right)+\sqrt{\kappa_{1}} \frac{\mu_{g i}\left(\phi c_{t}\right)_{m 1 i}}{k_{f h i}} \frac{\partial p_{p m 1}}{\partial(\beta t)}=0
\end{gathered}
$$

where, $\kappa_{1}$ is the permeability anisotropy factor of fracture, which is defined in Table A1.

In the outer region, the single porosity model is employed. Thus, the control equation for outer region is as following:

$$
\frac{1}{r} \frac{\partial}{\partial r}\left(r \frac{k_{m 2 h}}{k_{f h}} \frac{k_{f h} p}{\mu_{g} Z} \frac{\partial p_{m 2}}{\partial r}\right)+\frac{\partial}{\partial z}\left(\frac{k_{m 2 v}}{k_{f h}} \frac{k_{f h} p}{\mu_{g} Z} \frac{\partial p_{m 2}}{\partial z}\right)=\frac{\phi \mu_{g} c_{t}}{\alpha_{t} k_{f h}} \frac{k_{f h} p}{\mu_{g} Z} \frac{\partial p_{m 2}}{\partial t}
$$

where,

$$
p_{p m 2}=\frac{\mu_{g i} Z_{i}}{k_{f h i} p_{i}} \int_{p_{s c}}^{p_{m 2}} \frac{k_{f h} p}{\mu_{g} Z} d p
$$

The analogous assumptions are made as:

$$
\frac{k_{m 2 h}}{k_{f h}} \approx \frac{k_{m 2 h i}}{k_{f h i}}, \frac{k_{m 2 v}}{k_{f h}} \approx \frac{k_{m 2 v i}}{k_{f h i}}
$$

Thus, the control equation for outer region can be written as:

$$
\frac{1}{r} \frac{\partial}{\partial r}\left(r \frac{\partial p_{p m 2}}{\partial r}\right)+\frac{k_{m 2 v i}}{k_{m 2 h i}} \frac{\partial}{\partial z}\left(\frac{\partial p_{p m 2}}{\partial z}\right)=\frac{\left(\phi c_{t}\right)_{m 2 i} \mu_{g i}}{\alpha_{t} k_{m 2 h i}} \frac{k_{f h i}}{\left(\phi c_{t}\right)_{f i+m 1 i} \mu_{g i}} \frac{\left(\phi c_{t}\right)_{f i+m 1 i} \mu_{g i}}{k_{f h i}} \frac{\partial p_{p m 2}}{\partial(\beta t)}
$$

By using the dimensionless variables listed in Table A1, the governing equations can be transformed into dimensionless form as follows.

Governing equations of inner region:

$$
\begin{gathered}
\frac{1}{r_{D}} \frac{\partial}{\partial r_{D}}\left(r_{D} \frac{\partial p_{f D}}{\partial r_{D}}\right)+\frac{1}{h_{1 D}^{2}} \frac{\partial}{\partial z_{D}}\left(\frac{\partial p_{f D}}{\partial z_{D}}\right)=\omega \frac{\partial p_{f D}}{\partial t_{D}}-\frac{\lambda}{\sqrt{\kappa_{1}}}\left(p_{m 1 D}-p_{f D}\right) \\
\lambda\left(p_{m 1 D}-p_{f D}\right)+\sqrt{\kappa_{1}}(1-\omega) \frac{\partial p_{m 1 D}}{\partial t_{D}}=0
\end{gathered}
$$

Governing equations of outer region:

$$
\frac{1}{r_{D}} \frac{\partial}{\partial r_{D}}\left(r_{D} \frac{\partial p_{m 2 D}}{\partial r_{D}}\right)+\frac{1}{h_{2 D}^{2}} \frac{\partial}{\partial z_{D}}\left(\frac{\partial p_{m 2 D}}{\partial z_{D}}\right)=\frac{1}{\sigma} \frac{\partial p_{m 2 D}}{\partial t_{D}}
$$

Correspondingly, the initial conditions are:

$$
p_{f D}=p_{m 1 D}=p_{m 2 D}=0, t_{D}=0
$$

Inner boundary conditions are:

$$
\left.r_{D} \frac{\partial p_{f D}}{\partial r_{D}}\right|_{r_{D}=1}= \begin{cases}-\frac{1}{h_{w D D}} & , \quad\left|z_{D}-z_{w D}\right| \leq \frac{h_{w D}}{2} \\ 0 & ,\left|z_{D}-z_{w D}\right|>\frac{h_{w D}}{2}\end{cases}
$$


Outer boundary conditions are:

$$
\left.\frac{\partial p_{f D}}{\partial z_{D}}\right|_{z_{D}=0}=0,\left.\frac{\partial p_{f D}}{\partial z_{D}}\right|_{z_{D}=1}=0,\left.\frac{\partial p_{m 2 D}}{\partial z_{D}}\right|_{z_{D}=0}=0,\left.\frac{\partial p_{m 2 D}}{\partial z_{D}}\right|_{z_{D}=1}=0,\left.\frac{\partial p_{m 2 D}}{\partial r_{D}}\right|_{r_{D}=R_{e D}}=0
$$

Interface boundary conditions are:

$$
p_{f D}=p_{m 2 D}, \frac{\partial p_{f D}}{\partial r_{D}}=M \frac{\partial p_{m 2 D}}{\partial r_{D}}, r_{D}=R_{1 D}
$$

\begin{tabular}{|c|c|c|c|}
\hline Dimensionless Parameters & Expression & Dimensionless Parameters & Expression \\
\hline Dimensionless radius & $r_{D}=\frac{r}{r_{w}}$ & Dimensionless time & $t_{D}=\frac{\alpha_{t} k_{f h i} \beta t}{\mu_{\gamma i}\left[\left(\phi c_{t}\right)_{y i}+\left(\phi c_{t}\right)_{f i}\right]}$ \\
\hline Dimension inner region radius & $R_{1 D}=\frac{R_{1}}{r_{w}}$ & $\begin{array}{c}\text { Dimensionless natural fracture } \\
\text { pseudopressure }\end{array}$ & $p_{f D}=\frac{k_{f h i} h\left(p_{p i}-p_{p f}\right)}{\alpha_{p} q_{g} \mu_{g_{i} i} B_{g i}}$ \\
\hline $\begin{array}{l}\text { Dimensionless reservoir } \\
\text { radius }\end{array}$ & $R_{e D}=\frac{R_{e}}{r_{w}}$ & $\begin{array}{l}\text { Dimensionless matrix } \\
\text { pseudopressure in inner region }\end{array}$ & $p_{m 1 D}=\frac{k_{f h h} h\left(p_{p i}-p_{p 1 m}\right)}{\alpha_{p} q_{g} \mu_{g i} B_{g i}}$ \\
\hline $\begin{array}{c}\text { Dimensionless vertical } \\
\text { distance }\end{array}$ & $z_{D}=\frac{z}{h}$ & $\begin{array}{l}\text { Dimensionless matrix } \\
\text { pseudopressure in outer region }\end{array}$ & $p_{m 2 D}=\frac{k_{f h i} h\left(p_{p i}-p_{p 2 m}\right)}{\alpha_{p} q_{g} \mu_{g i} B_{g i}}$ \\
\hline $\begin{array}{c}\text { Dimensionless vertical } \\
\text { distance of mid-perforation }\end{array}$ & $z_{w D}=\frac{z_{w}}{h}$ & Dimensionless production rate & $q_{w D}=\frac{q_{g}(t) \alpha_{p} \mu_{g i} B_{g i}}{k_{f h i} h\left[p_{p}\left(p_{i}\right)-p_{p}\left(p_{w f}\right)\right]}$ \\
\hline $\begin{array}{c}\text { Dimensionless reservoir } \\
\text { thickness }\end{array}$ & $h_{D}=\frac{h}{r_{w}}$ & $\begin{array}{c}\text { Storativity ratio of natural } \\
\text { fracture, } \omega\end{array}$ & $\omega=\frac{\left(\phi c_{t}\right)_{f}}{\left(\phi c_{t}\right)_{f+m 1}}$ \\
\hline $\begin{array}{c}\text { Dimensionless perforation } \\
\text { thickness }\end{array}$ & $h_{w D}=\frac{h_{w}}{h}$ & $\begin{array}{l}\text { Interporosity flow coefficient } \\
\text { between fractures and matrix, } \lambda\end{array}$ & $\lambda=\alpha \frac{K_{f}}{K_{m 1}} r_{w}^{2}$ \\
\hline $\begin{array}{l}\text { Permeability anisotropy factor } \\
\text { for fracture }\end{array}$ & $\kappa_{1}=\frac{k_{f h}}{k_{f v}}$ & $\begin{array}{l}\text { Diffusivity ration between outer } \\
\text { and inner regions, } \delta\end{array}$ & $\sigma=\frac{k_{m 2 h i}}{\left(\phi c_{t}\right)_{m 2 i} \mu_{g i}} / \frac{k_{f h i}}{\left(\phi c_{t}\right)_{f i+m 1 i} \mu_{g i}}$ \\
\hline $\begin{array}{l}\text { Permeability anisotropy factor } \\
\text { for matrix in outer region }\end{array}$ & $\kappa_{2}=\frac{k_{m 2 h}}{k_{m 2 v}}$ & $\begin{array}{l}\text { Mobility ratio between outer } \\
\text { and inner regions, } M\end{array}$ & $M=\frac{k_{m 2 h i}}{\left(\phi c_{t}\right)_{m 2 i} \mu_{g i}} / \frac{k_{f h i}}{\left(\phi c_{t}\right)_{f i+m 1 i} \mu_{g i}}$ \\
\hline
\end{tabular}

Table A1. The definitions of dimensionless parameters.

\section{Appendix B. Derivation of the Solution}

Firstly, the Laplace transforms with respect to $t_{\mathrm{D}}$ for dimensionless fracture and matrix pseudopressure are defined as following, respectively:

$$
\begin{aligned}
\tilde{p}_{f D}\left(r_{D}, z_{D}, s\right) & =\int_{0}^{+\infty} e^{-s t_{D}} p_{f D}\left(r_{D}, z_{D}, t_{D}\right) d t_{D} \\
\tilde{p}_{m 1 D}\left(r_{D}, z_{D}, s\right) & =\int_{0}^{+\infty} e^{-s t_{D}} p_{m 1 D}\left(r_{D}, z_{D}, t_{D}\right) d t_{D} \\
\tilde{p}_{m 2 D}\left(r_{D}, z_{D}, s\right) & =\int_{0}^{+\infty} e^{-s t_{D}} p_{m 2 D}\left(r_{D}, z_{D}, t_{D}\right) d t_{D}
\end{aligned}
$$

Based on the Laplace transforms, the control equations in Laplace space are:

$$
\begin{aligned}
& \frac{1}{r_{D}} \frac{\partial}{\partial r_{D}}\left(r_{D} \frac{\partial \widetilde{p}_{f D}}{\partial r_{D}}\right)+\frac{1}{h_{1 D}^{2}} \frac{\partial}{\partial z_{D}}\left(\frac{\partial \widetilde{p}_{f D}}{\partial z_{D}}\right)=s f(s) \widetilde{p}_{f D} \\
& \frac{1}{r_{D}} \frac{\partial}{\partial r_{D}}\left(r_{D} \frac{\partial \widetilde{p}_{m 2 D}}{\partial r_{D}}\right)+\frac{1}{h_{2 D}^{2}} \frac{\partial}{\partial z_{D}}\left(\frac{\partial \widetilde{p}_{m 2 D}}{\partial z_{D}}\right)=\frac{1}{\sigma} s \widetilde{p}_{m 2 D}
\end{aligned}
$$

where, $h_{1 D}=h_{D} \sqrt{\kappa_{1}}, h_{2 D}=h_{D} \sqrt{\kappa_{2}}, f(s)=\frac{\lambda+\sqrt{\kappa_{1}} \omega(1-\omega) s}{\lambda+\sqrt{\kappa_{1}}(1-\omega) s}$. 
To eliminate the variable $z_{\mathrm{D}}$ in the control equations, the finite Fourier cosine transforms are defined as follows:

$$
\bar{p}_{f D}\left(u_{n}\right)=\int_{0}^{1} p_{f D} \cos \left(u_{n} z_{D}\right) d z_{D}, \bar{p}_{m 2 D}\left(u_{n}\right)=\int_{0}^{1} p_{m 2 D} \cos \left(u_{n} z_{D}\right) d z_{D}
$$

Thus, the inverse Fourier transforms are:

$$
p_{f D}\left(z_{D}\right)=\sum_{n=0}^{\infty} \frac{\cos \left(u_{n} z_{D}\right)}{N(n)} \bar{p}_{f D}\left(u_{n}\right), p_{m 2 D}\left(z_{D}\right)=\sum_{n=0}^{\infty} \frac{\cos \left(u_{n} z_{D}\right)}{N(n)} \bar{p}_{m 2 D}\left(u_{n}\right)
$$

where,

$$
N(n)=\int_{0}^{1} \cos ^{2}\left(u_{n} z_{D}\right) d z_{D}=\left\{\begin{array}{l}
1, n=0 \\
\frac{1}{2}, n=1,2,3, \ldots
\end{array}\right.
$$

Applying the Fourier transform presented by Equation (A25), we can obtain:

$$
\begin{aligned}
& \frac{1}{r_{D}} \frac{\partial}{\partial r_{D}}\left(r_{D} \frac{\partial \overline{\bar{p}}_{f D}}{\partial r_{D}}\right)-\frac{u_{n}^{2}}{h_{1 D}^{2}} \overline{\bar{p}}_{f D}=s f(s) \overline{\bar{p}}_{f D} \\
& \frac{1}{r_{D}} \frac{\partial}{\partial r_{D}}\left(r_{D} \frac{\partial \overline{\bar{p}}_{m 2 D}}{\partial r_{D}}\right)-\frac{u_{n}^{2}}{h_{2 D}^{2}} \overline{\bar{p}}_{m 2 D}=\frac{1}{\sigma} \overline{\bar{p}}_{m 2 D}
\end{aligned}
$$

and the definite conditions can be written as:

$$
\begin{gathered}
\left.\frac{\partial \overline{\bar{p}}_{m 2 D}}{\partial r_{D}}\right|_{r_{D}=R_{e D}}=0 \\
\left.r_{D} \frac{\partial \overline{\bar{p}}_{f D}}{\partial r_{D}}\right|_{r_{D}=1}=-\frac{1}{s h_{w D}} \int_{z_{w D}-\frac{h_{w D}}{2}}^{z_{w D}+\frac{h_{w D}}{2}} \cos \left(u_{n} z_{D}\right) d z_{D}=-\frac{1}{s} \frac{\sin \left(\frac{1}{2} u_{n} h_{w D}\right)}{\frac{1}{2} u_{n} h_{w D}} \cos \left(u_{n} z_{w D}\right) \\
\overline{\bar{p}}_{f D}=\overline{\bar{p}}_{m 2 D} \frac{\partial \overline{\bar{p}}_{f D}}{\partial r_{D}}=M \frac{\partial \overline{\bar{p}}_{m 2 D}}{\partial r_{D}}, r_{D}=R_{1 D} .
\end{gathered}
$$

The general solutions of Equations (A28) and (A29) are:

$$
\begin{gathered}
\overline{\bar{p}}_{f D}=A I_{0}\left(r_{D} q_{n}\right)+B K_{0}\left(r_{D} q_{n}\right), q_{n}=\sqrt{s f(s)+\frac{u_{n}^{2}}{h_{1 D}^{2}}} \\
\overline{\bar{p}}_{m 2 D}=C I_{0}\left(r_{D} T_{n}\right)+D K_{0}\left(r_{D} T_{n}\right), T_{n}=\sqrt{\frac{s}{\sigma}+\frac{u_{n}^{2}}{h_{2 D}^{2}}}
\end{gathered}
$$

Combining the conditions of Equations (A30) to (A32), the solution in Laplace and Fourier domain is:

$$
\overline{\bar{p}}_{f D}=\frac{1}{s} \frac{\sin \left(\frac{1}{2} u_{n} h_{w D}\right)}{\frac{1}{2} u_{n} h_{w D}} \frac{1}{q_{n}}\left[\frac{E_{n} I_{0}\left(r_{D} q_{n}\right)+F_{n} K_{0}\left(r_{D} q_{n}\right)}{F_{n} K_{1}\left(q_{n}\right)-E_{n} I_{1}\left(q_{n}\right)}\right] \cos \left(u_{n} z_{w D}\right)
$$

where,

$$
E_{n}=q_{n} G_{n} K_{1}\left(R_{1 D} q_{n}\right)+M T_{n} H_{n} K_{0}\left(R_{1 D} q_{n}\right)
$$




$$
\begin{aligned}
& F_{n}=q_{n} G_{n} I_{1}\left(R_{1 D} q_{n}\right)-M T_{n} H_{n} I_{0}\left(R_{1 D} q_{n}\right) \\
& G_{n}=\frac{K_{1}\left(R_{e D} T_{n}\right)}{I_{1}\left(R_{e D} T_{n}\right)} I_{0}\left(R_{1 D} T_{n}\right)+K_{0}\left(R_{1 D} T_{n}\right) \\
& H_{n}=\frac{K_{1}\left(R_{e D} T_{n}\right)}{I_{1}\left(R_{e D} T_{n}\right)} I_{1}\left(R_{1 D} T_{n}\right)-K_{1}\left(R_{1 D} T_{n}\right)
\end{aligned}
$$

By the utility of inverse Fourier transforms, we can obtain:

$$
\begin{aligned}
s \widetilde{p}_{f D} & =\frac{1}{q_{0}}\left[\frac{E_{0} I_{0}\left(r_{D} q_{0}\right)+F_{0} K_{0}\left(r_{D} q_{0}\right)}{F_{0} K_{1}\left(q_{0}\right)-E_{0} I_{1}\left(q_{0}\right)}\right] \\
& +2 \sum_{n=1}^{\infty} \frac{\sin \left(\frac{1}{2} u_{n} h_{w D}\right)}{\frac{1}{2} u_{n} h_{w D}} \frac{1}{q_{n}}\left[\frac{E_{n} I_{0}\left(r_{D} q_{n}\right)+F_{n} K_{0}\left(r_{D} q_{n}\right)}{F_{n} K_{1}\left(q_{n}\right)-E_{n} I_{1}\left(q_{n}\right)}\right] \cos \left(u_{n} z_{w D}\right) \cos \left(u_{n} z_{D}\right)
\end{aligned}
$$

For limited-entry well, the equivalent pressure point can be written as follows by integral-averaging method.

$$
s \widetilde{p}_{w D}=\frac{1}{q_{0}}\left[\frac{E_{0} I_{0}\left(r_{D} q_{0}\right)+F_{0} K_{0}\left(r_{D} q_{0}\right)}{F_{0} K_{1}\left(q_{0}\right)-E_{0} I_{1}\left(q_{0}\right)}\right]+2 \sum_{n=1}^{\infty} \frac{\sin ^{2}\left(\frac{1}{2} u_{n} h_{w D}\right)}{\left(\frac{1}{2} u_{n} h_{w D}\right)^{2}} \frac{1}{q_{n}}\left[\frac{E_{n} I_{0}\left(r_{D} q_{n}\right)+F_{n} K_{0}\left(r_{D} q_{n}\right)}{F_{n} K_{1}\left(q_{n}\right)-E_{n} I_{1}\left(q_{n}\right)}\right] \cos ^{2}\left(u_{n} z_{w D}\right)
$$

\section{References}

1. Chen, Z.; Liao, X.; Zhao, X.; Lv, S.; Dou, X.; Guo, X.; Li, L.; Zang, J. Development of a trilinear flow model for carbon sequestration in depleted shale. Soc. Petrol. Eng. 2015. [CrossRef]

2. Jia, P.; Cheng, L.; Huang, S. A semi-analytical model for the flow behavior of naturally fractured formations with multi-scale fracture networks. J. Hydrol. 2016, 537, 208-220. [CrossRef]

3. Busch, A.; Alles, S.; Gensterblum, Y.; Prinz, D.; Dewhurst, D.N.; Raven, M.D.; Stanjek, H.; Krooss, B.M. Carbon dioxide storage potential of shales. Int. J. Greenh. Gas Contr. 2008, 2, 297-308. [CrossRef]

4. Xu, B.; Haghighi, M.; Li, X. Development of new type curves for production analysis in naturally fractured shale gas/tight gas reservoirs. J. Pet. Sci. Eng. 2013, 105, 107-115. [CrossRef]

5. Ramagost, B.P.; Farshad, F.F. P/Z Abnormally Pressured Gas Reservoirs. In Proceedings of the SPE Annual Technical Conference and Exhibition, San Antonio, TX, USA, 4-7 October 1981.

6. Fankun, M.; Qun, L.; Dongbo, H. Production performance analysis for deviated wells in composite carbonate gas reservoirs. J. Nat. Gas Sci. Eng. 2018, 56, 333-343.

7. Hurst, W. Interference between oil fields. Transactions, AIME, Volume 219, 1960, pp. 175-192. Available online: https://www.onepetro.org/general/SPE-1335-Gaddress (accessed on 30 April 2019).

8. Olarewaju, J.S.; Lee, W.J. An analytical model for composite reservoirs produced at either constant bottomhole pressure or constant rate. Presented at the 62nd Annual Technical Conference and Exhibition, Dallas, TX, USA, 27-30 September 1987.

9. Olarewaju, J.S.; Lee, J.W. A comprehensive application of a composite reservoir model to pressure-transient analysis. SPE Reserv. Eng. 1989, 4, 325-331. [CrossRef]

10. Prado, L.R.; Da Prat, G. An analytical solution for unsteady liquid flow in a reservoir with a uniformly fractured zone around the well. Soc. Petrol. Eng. 1987. [CrossRef]

11. Satman, A. Pressure-Transient Analysis of a Composite Naturally Fractured Reservoir. Soc. Petrol. Eng. 1991. [CrossRef]

12. Olarewaju, J.S.; Lee, W.J. Rate behavior of composite dual-porosity reservoirs. Presented at the Production Operations Symposium, Oklahoma City, OK, USA, 7-9 April 1991.

13. Olarewaju, J.S.; Lee, W.J.; Lancaster, D.E. Type and decline-curve analysis with composite models. SPE Form. Eval. 1991, 6, 79-85. [CrossRef]

14. Kikani, J.; Walkup, G.W. Analysis of pressure-transient tests for composite naturally fractured reservoirs. Soc. Petrol. Eng. 1991. [CrossRef]

15. Kuchuk, F.J.; Habashy, T.M. Solution of pressure diffusion in radially composite reservoirs. Trans. Porous Media 1995, 19, 199-232. [CrossRef]

16. Zhao, Y.L.; Zhang, L.H.; Liu, Y.H.; Hu, S.U.; Liu, Q.G. Transient pressure analysis of fractured well in bi-zonal gas reservoirs. J. Hydrol. 2015, 524, 89-99. [CrossRef] 
17. Wang, H.; Ran, Q.; Liao, X. Pressure transient responses study on the hydraulic volume fracturing vertical well in stress-sensitive tight hydrocarbon reservoirs. Int. J. Hydrogen Energy 2017, 42, 18343-18349. [CrossRef]

18. Xu, J.; Guo, C.; Teng, W. Production performance analysis of tight oil/gas reservoirs considering stimulated reservoir volume using elliptical flow. J. Nat. Gas Sci. Eng. 2015, 26, 827-839. [CrossRef]

19. Muskat, M. The Flow of Homogeneous Fluids through Porous Media; J. W. Edwards Inc.: Ann Arbor, MI, USA, 1937.

20. Nisle, R.G. The effect of partial penetration on pressure build-up in oil wells. Trans. AIME 1958, 213, 85-90.

21. Brons, F.; Marting, V.E. The effect of restricted flow entry on well productivity. J. Pet. Tech. 1961, 13. [CrossRef]

22. Odeh, A.S. Steady-state. flow capacity of wells with limited entry to flow. SPE J. 1968, 8, 43-51. [CrossRef]

23. Kazemi, H.; Seth, M.S. Effect of Anisotropy and stratification on pressure transient analysis of wells with restricted flow entry. J. Pet. Tech. 1969, 21, 639-647. [CrossRef]

24. Streltsova, T.D. Pressure drawdown in a well with limited flow entry. J. Pet. Tech. 1979, 31, 1469-1476. [CrossRef]

25. Streltsova, T.D. Pressure transient analysis for afterflow-dominated wells producing from a reservoir with a gas cap. J. Pet. Tech. 1981, 33, 743-754. [CrossRef]

26. Streltsova, T.D. Well pressure behavior of a naturally fractured reservoir. SPE J. 1983, 23, 769-780. [CrossRef]

27. Dougherty, D.E.; Babu, D.K. Flow to a partially penetrating well in a double-porosity reservoir. Water Resour. Res. 1984, 20, 1116-1122. [CrossRef]

28. Bui, T.D.; Mamora, D.D.; Lee, W.J. Transient pressure analysis for partially penetrating wells in naturally fractured reservoirs. Soc. Petrol. Eng. 2000. [CrossRef]

29. Slimani, K.; Tiab, D. Pressure transient analysis of partially penetrating wells in a naturally fractured reservoir. Petrol. Soc. Can. 2008. [CrossRef]

30. Mishra, P.K.; Vesselinov, V.V.; Neuman, S.P. Radial flow to a partially penetrating well with storage in an anisotropic confined aquifer. J. Hydrol. 2012, 448, 448-449. [CrossRef]

31. Biryukov, D.; Kuchuk, F.J. Pressure transient solutions to mixed boundary value problems for partially open wellbore geometries in porous media. J. Petrol. Sci. Eng. 2012, 96-97, 162-175. [CrossRef]

32. Javandel, I. A semi-analytical solution for partial penetration in two-layer aquifers. Water Resour. Res. 2012, 16, 1099-1106. [CrossRef]

33. Dejam, M.; Hassanzadeh, H.; Chen, Z. Semi-analytical. solutions for a partially penetrated well with wellbore storage and skin effects in a double-porosity system with a gas cap. Trans. Porous Media 2013, 100, 159-192. [CrossRef]

34. Dou, X.; Xinwei, L.; Xiaoliang, Z.; Tianyi, Z.; Zhiming, C.; Weiyan, R.; Rui, Z. Analysis on Traditional Reserve Estimation Methods in Stress-Sensitive Gas Reservoir: Error Analysis and Modification. In Proceedings of the SPE Nigeria Annual International Conference and Exhibition, Lagos, Nigeria, 4-6 August 2015.

35. Xu, W.; Wang, X.; Hou, X.; Clive, K.; Zhou, Y. Transient analysis for fractured gas wells by modified pseudo-functions in stress-sensitive reservoirs. J. Nat. Gas Sci. Eng. 2016, 35, 1129-1138. [CrossRef]

36. Luo, W.; Tang, C.; Feng, Y. Mechanism of fluid flow along a dynamic conductivity fracture with pressure-dependent permeability under constant wellbore pressure. J. Petrol. Sci. Eng. 2018, 166, 465-475. [CrossRef]

37. Guo, P.; Sun, Z.; Peng, C.; Chen, H.; Ren, J. Transient-Flow Modeling of Vertical Fractured Wells with Multiple Hydraulic Fractures in Stress-Sensitive Gas Reservoirs. Appl. Sci. 2019, 9, 1359. [CrossRef]

38. Al-Hussainy, R.; Ramey, H.J., Jr.; Crawford, P.B. The flow of real gases through porous media. J. Petrol. Technol. 1966, 18, 624-636. [CrossRef]

39. Russell, D.; Goodrich, J.; Perry, G.; Bruskotter, J. Methods for predicting gas well performance. J. Pet. Tech. 1966, 18, 99-108. [CrossRef]

40. Agarwal, R.A. "Real gas pseudo-time"-A new function for pressure buildup analysis of MHF gas wells. Presented at the SPE Annual Technical Conference and Exhibition, Las Vegas, NV, USA, 23-26 September 1979.

41. Lee, W.J.; Holditch, S.A. Application of pseudotime to buildup test analysis of lowpermeability gas wells with long-duration wellbore storage distortion. J. Petrol. Technol. 1982, 34, 2877-2887. [CrossRef]

42. Ye, P.; Luis, F.A.H. A density-diffusivity approach for the unsteady state analysis of natural gas reservoirs. J. Nat. Gas Sci. Eng. 2012, 7, 22-34. [CrossRef]

43. Aguilera, R. Effect of fracture compressibility on gas-in-place calculations of stress-sensitive naturally fractured reservoirs. Soc. Petrol. Eng. 2006. [CrossRef]

44. Warren, J.E.; Root, P.J. The behavior of naturally fractured reservoirs. SPE J. 1963, 3, 245-255. [CrossRef] 
45. Van Everdingen, A.F.; Hurst, W. The application of the Laplace transformation to flow problems in reservoirs. Trans. AIME 1949, 1. [CrossRef]

46. Stehfest, H. Numerical Inversion of Laplace Transforms. Commun. ACM 1970, 13, 47-49. [CrossRef]

(C) 2019 by the authors. Licensee MDPI, Basel, Switzerland. This article is an open access article distributed under the terms and conditions of the Creative Commons Attribution (CC BY) license (http://creativecommons.org/licenses/by/4.0/). 